\title{
The ASSET intercomparison of ozone analyses: method and first results
}

\author{
A. J. Geer ${ }^{1,10}$, W. A. Lahoz ${ }^{1}$, S. Bekki ${ }^{2}$, N. Bormann ${ }^{3}$, Q. Errera ${ }^{4}$, H. J. Eskes ${ }^{5}$, D. Fonteyn ${ }^{4}$, D. R. Jackson ${ }^{6}$, \\ M. N. Juckes ${ }^{7}$, S. Massart ${ }^{8}$, V.-H. Peuch ${ }^{9}$, S. Rharmili ${ }^{2}$, and A. Segers ${ }^{5}$ \\ ${ }^{1}$ Data Assimilation Research Centre, University of Reading, Reading, UK \\ ${ }^{2}$ CNRS Service Aeronomie, Université Pierre et Marie Curie, Paris, France \\ ${ }^{3}$ European Centre for Medium-Range Weather Forecasts, Reading, UK \\ ${ }^{4}$ Institut d'Aéronomie Spatiale de Belgique, Brussels, Belgium \\ ${ }^{5}$ Royal Netherlands Meteorological Institute, De Bilt, The Netherlands \\ ${ }^{6}$ Met Office, Exeter, UK \\ ${ }^{7}$ British Atmospheric Data Centre, Rutherford Appleton Laboratory, Chilton, nr Didcot, UK \\ ${ }^{8}$ CERFACS, Toulouse, France \\ ${ }^{9}$ CNRM-GAME, Météo-France and CNRS URA 1357, Toulouse, France \\ ${ }^{10}$ Now at European Centre for Medium-Range Weather Forecasts, Reading, UK
}

Received: 6 February 2006 - Published in Atmos. Chem. Phys. Discuss.: 7 June 2006

Revised: 4 October 2006 - Accepted: 28 November 2006 - Published: 5 December 2006

\begin{abstract}
This paper aims to summarise the current performance of ozone data assimilation (DA) systems, to show where they can be improved, and to quantify their errors. It examines 11 sets of ozone analyses from 7 different DA systems. Two are numerical weather prediction (NWP) systems based on general circulation models (GCMs); the other five use chemistry transport models (CTMs). The systems examined contain either linearised or detailed ozone chemistry, or no chemistry at all. In most analyses, MIPAS (Michelson Interferometer for Passive Atmospheric Sounding) ozone data are assimilated; two assimilate SCIAMACHY (Scanning Imaging Absorption Spectrometer for Atmospheric Chartography) observations instead. Analyses are compared to independent ozone observations covering the troposphere, stratosphere and lower mesosphere during the period July to November 2003.
\end{abstract}

Biases and standard deviations are largest, and show the largest divergence between systems, in the troposphere, in the upper-troposphere/lower-stratosphere, in the upperstratosphere and mesosphere, and the Antarctic ozone hole region. However, in any particular area, apart from the troposphere, at least one system can be found that agrees well with independent data. In general, none of the differences can be linked to the assimilation technique (Kalman filter, three or four dimensional variational methods, direct inversion) or

Correspondence to: A. J. Geer

(alan.geer@ecmwf.int) the system (CTM or NWP system). Where results diverge, a main explanation is the way ozone is modelled. It is important to correctly model transport at the tropical tropopause, to avoid positive biases and excessive structure in the ozone field. In the southern hemisphere ozone hole, only the analyses which correctly model heterogeneous ozone depletion are able to reproduce the near-complete ozone destruction over the pole. In the upper-stratosphere and mesosphere (above $5 \mathrm{hPa}$ ), some ozone photochemistry schemes caused large but easily remedied biases. The diurnal cycle of ozone in the mesosphere is not captured, except by the one system that includes a detailed treatment of mesospheric chemistry. These results indicate that when good observations are available for assimilation, the first priority for improving ozone DA systems is to improve the models.

The analyses benefit strongly from the good quality of the MIPAS ozone observations. Using the analyses as a transfer standard, it is seen that MIPAS is $\sim 5 \%$ higher than HALOE (Halogen Occultation Experiment) in the mid and upper stratosphere and mesosphere (above $30 \mathrm{hPa}$ ), and of order $10 \%$ higher than ozonesonde and HALOE in the lower stratosphere $(100 \mathrm{hPa}$ to $30 \mathrm{hPa})$. Analyses based on SCIAMACHY total column are almost as good as the MIPAS analyses; analyses based on SCIAMACHY limb profiles are worse in some areas, due to problems in the SCIAMACHY retrievals. 


\section{Introduction}

The Assimilation of ENVISAT Data project (ASSET, http: //darc.nerc.ac.uk/asset) aims to provide analyses of atmospheric chemical constituents, based on the assimilation of observations from ENVISAT, and to develop chemical weather and UV forecasting capabilities. Data are assimilated into a variety of different systems, including chemical transport models (CTMs) with detailed chemistry or linearised chemistry, and Numerical Weather Prediction (NWP) systems based on General Circulation Models (GCMs), either with linearised chemistry, or coupled to detailedchemistry CTMs. Data assimilation techniques (see e.g., Kalnay, 2003) include three and four-dimensional variational data assimilation (3-D-Var and 4-D-Var) and the Kalman Filter (KF). It is hoped that, by confronting these various models and techniques with the newly available ENVISAT observations, it will be possible both to gain an understanding of their strengths and weaknesses, and to make new developments. A number of ozone analyses have been created within the ASSET project; this paper compares them to independent observations and to ozone analyses from outside the project. The aim is to summarise the current performance of ozone data assimilation systems, to show where they can be improved, and to quantify their errors.

Datasets of assimilated ozone will be useful for research and monitoring of ozone depletion (e.g., WMO, 2003), tropospheric pollution, and UV fluxes, and beyond this, ozone assimilation is expected to bring a number of benefits in NWP. First, in the upper-troposphere/lower-stratosphere (UTLS), ozone has a photochemical relaxation time of order 100 days, and it can be used as a tracer to infer atmospheric motions using 4D-Var (e.g., Riishøjgaard, 1996; Peuch et al., 2000). Second, NWP systems have typically used a zonal mean ozone climatology in modelling heating rates and in the forward radiative transfer calculations used in the assimilation of satellite radiances such as those from the Atmospheric Infrared Sounder (AIRS). An estimate of the true 3-D ozone distribution is likely to improve these calculations. Experiments at ECMWF found that variations in ozone amounts of $\sim 10$ to $20 \%$ could result in changes in modelled tropical UTLS temperatures of up to $4 \mathrm{~K}$ (Cariolle and Morcrette, 2006). The diurnal cycle of ozone is important in the middle atmosphere. Model runs with diurnally varying ozone show temperature differences of up to $3 \mathrm{~K}$ in the stratosphere, compared to those with climatological ozone (Sassi et al., 2005). A prognostic ozone field also allows the modelling of feedbacks between radiation, chemistry and dynamics, and this is expected to improve forecasts, especially over longer timescales. However, no study has yet found a clear benefit in terms of forecast scores (e.g., Morcrette, 2003). Finally, in order to simulate a good ozone distribution, models used in assimilation systems must be able to simulate stratospheric transport well; problems are often revealed when these models are confronted with real observations (e.g., Geer et al., 2006b).

Different approaches can be used for ozone data assimilation and the choice will vary depend upon the application. For studies of chemistry and transport, assimilation systems can be based on chemical transport models. These rely on operationally-produced analyses of wind and temperature (such as those from ECMWF) to advect chemical constituents. If chemistry is treated approximately, these models are extremely fast and can be used to assimilate many months of observations in a few days on a desktop computer. Including a detailed chemistry scheme, with dozens of constituents and hundreds of reactions, allows a more accurate simulation of the ozone distribution, but is slower. The CTM approach has been very popular for ozone analysis systems (e.g., Fisher and Lary, 1995; Khattatov et al., 2000; Elbern and Schmidt, 2001; Errera and Fonteyn, 2001; Stajner et al., 2001; Chipperfield et al., 2002; Fierli et al., 2002; Cathala et al., 2003; Eskes et al., 2003, 2005a; El Amraoui et al., 2004; Massart et al., 2005; Segers et al., 2005a; Wargan et al., 2005). It is also possible to introduce a prognostic ozone field as a relatively straightforward upgrade to an existing NWP system (e.g., Struthers et al., 2002; Dethof and Hólm, 2004; Geer et al., 2006b), though ozone assimilation then becomes part of a very large operational system, requiring a supercomputer. Much work is still required to confirm the proposed benefits (listed in the previous paragraph) of including ozone directly into NWP systems. One alternative approach is to couple CTMs, with a detailed description of chemistry, to GCM-based NWP systems, such that feedbacks between chemistry, dynamics and radiation can be maintained.

Current operational satellite ozone observations include the Total Ozone Mapping Spectrometer (TOMS), measuring total column ozone, and the Solar Backscatter Ultraviolet (SBUV) instrument (e.g., Bhartia et al., 1996), which produces vertical profiles. ENVISAT, launched in 2002, provides the instruments MIPAS (Michelson Interferometer for Passive Atmospheric Sounding), SCIAMACHY (Scanning Imaging Absorption Spectrometer for Atmospheric Chartography) and GOMOS (Global Ozone Monitoring by Occultation of Stars). Between them, these instruments measure many species beyond ozone, and vertical resolution is much improved over the operational instruments. For example, MIPAS has roughly twice the vertical resolution of SBUV in the stratosphere (see e.g. Fig. 2, Wargan et al., 2005). Dethof (2003a) and Wargan et al. (2005) show that ozone analyses are significantly better when MIPAS observations are assimilated, compared to experiments using only total column or low-vertical resolution observations like TOMS or SBUV.

The ASSET project is based around assimilating the data from ENVISAT. The EOS-Aura satellite, launched in 2004, has instruments with similar capabilities. Research instruments such as those on ENVISAT and Aura do, however, have a limited lifetime and data products are not always available quickly enough to be included in operational NWP schedules. Hence research satellite data is often best used 
Table 1. Principal features of the analysis systems and climatologies. See Sect. 2 for details.

\begin{tabular}{|c|c|c|c|c|c|c|c|c|}
\hline Name & Type & Winds & $\begin{array}{l}\text { Lon/Lat } \\
\text { resolution } \\
\text { (degrees) }\end{array}$ & $\begin{array}{l}\text { Levels } \\
\text { from } \\
100 \text { to } \\
1 \mathrm{hPa}\end{array}$ & $\begin{array}{l}\text { Data } \\
\text { assim- } \\
\text { ilation } \\
\text { scheme }\end{array}$ & $\begin{array}{l}\text { Ozone observa- } \\
\text { tions }\end{array}$ & $\begin{array}{l}\text { Ozone photo- } \\
\text { chemistry }\end{array}$ & $\begin{array}{l}\text { Heterogeneous } \\
\text { ozone chem- } \\
\text { istry }\end{array}$ \\
\hline $\begin{array}{l}\text { ECMWF opera- } \\
\text { tional }\end{array}$ & NWP & & $\begin{array}{l}0.5 / 0.5 \\
\text { (approx.) }\end{array}$ & 21 & 4D-Var & $\begin{array}{l}\text { SBUV, GOME } \\
\text { total columns, } \\
\text { MIPAS from } \\
7 / 10 / 2003\end{array}$ & Cariolle v1.2 & $T<195 \mathrm{~K}$ term \\
\hline ECMWF MIPAS & NWP & & $\begin{array}{l}0.5 / 0.5 \\
\text { (approx.) }\end{array}$ & 21 & 4D-Var & $\begin{array}{l}\text { SBUV, GOME } \\
\text { total columns, } \\
\text { MIPAS } \\
\text { throughout }\end{array}$ & Cariolle v1.2 & $T<195 \mathrm{~K}$ term \\
\hline DARC/Met Office & NWP & & $3.75 / 2.5$ & 18 & 3-D-Var & MIPAS & Cariolle v1.0 & Cold tracer \\
\hline $\begin{array}{l}\text { KNMI SCIA- } \\
\text { MACHY profiles }\end{array}$ & CTM & ECMWF & $3.0 / 2.0$ & 21 & $\begin{array}{l}\text { sub- } \\
\text { optimal } \\
\text { KF }\end{array}$ & $\begin{array}{l}\text { SCIAMACHY } \\
\text { profiles }\end{array}$ & Cariolle v1.0 & Cold tracer \\
\hline BASCOE v3d24 & СТM & ECMWF & $5.0 / 3.75$ & 21 & 4D-Var & MIPAS & 57 species & PSCBox \\
\hline BASCOE v3q33 & CTM & ECMWF & $5.0 / 3.75$ & 21 & 4D-Var & MIPAS & 57 species & $\begin{array}{l}\text { PSC } \\
\text { parametrization }\end{array}$ \\
\hline $\begin{array}{l}\text { MOCAGE- } \\
\text { PALM/Cariolle }\end{array}$ & CTM & Arpege & $2.0 / 2.0$ & $\begin{array}{l}17 \quad \text { to } \\
5 \mathrm{hPa})\end{array}$ & $\begin{array}{l}\text { 3-D- } \\
\text { FGAT }\end{array}$ & MIPAS & Cariolle v2.1 & $T<195 \mathrm{~K}$ term \\
\hline $\begin{array}{l}\text { MOCAGE- } \\
\text { PALM/Reprobus }\end{array}$ & CTM & Arpege & $2.0 / 2.0$ & $\begin{array}{l}17 \quad \text { to } \\
5 \mathrm{hPa})\end{array}$ & $\begin{array}{l}\text { 3-D- } \\
\text { FGAT }\end{array}$ & MIPAS & $\begin{array}{l}\text { REPROBUS } \\
\text { (Lefèvre et al., } \\
\text { 1994) }\end{array}$ & $\begin{array}{l}\text { Carslaw et al. } \\
\text { (1995) }\end{array}$ \\
\hline
\end{tabular}

for re-analyses, and to help improve models and assimilation systems such that the operational observations may be assimilated more successfully.

There have been a number of previous intercomparisons between the ozone distributions in chemistry-climate models (Austin et al., 2003) and in CTMs (e.g., Bregman et al., 2001; Roelofs et al., 2003). These, and numerous other individual studies, have illustrated the importance of correctly modelling ozone transport. It is also well known that in CTMs driven by analysed wind fields, the stratospheric BrewerDobson circulation transports constituents far too quickly (Schoeberl et al., 2003).
This is the first time an intercomparison of ozone assimilation systems has been made. Historically, intercomparisons between GCMs have tried to standardise as many factors as possible (e.g. Gates, 1992; Pawson et al., 2000). Compared to GCMs, there are many more areas where assimilation systems can diverge, such as in the assimilated observations (also their errors and the quality control applied to them), the assimilation technique, and the specification of background errors. This makes it much trickier to understand differences between experiments. 
Since an intercomparison of assimilation systems is bound to be difficult, why not simply rely on model-only results? The reason is that assimilation systems often perform very differently to models. This can result in problems: well known examples include the spin-down of tropical moisture in the ECMWF system (Uppala et al., 2005) and the excessive stratospheric Brewer-Dobson circulation produced by assimilated wind datasets. In contrast, some problems found in free-running models can be corrected, if not totally eliminated, by the regular insertion of observational data. For example, stratospheric tracer gradients become much more realistic in assimilation experiments compared to free model runs (e.g. Chipperfield et al., 2002). Hence, data assimilation systems need to be separately validated.

For this intercomparison, ozone analyses have been made for the period July to November 2003, chosen because of the availability of good quality MIPAS data. This period included one of the largest ozone holes on record (e.g., Dethof, 2003a), caused by relatively low temperatures in a fairly stable southern hemisphere $(\mathrm{SH})$ polar vortex, which was destroyed by the usual top-down break-up during October and November (Lahoz et al., 2006).

Eleven analysis runs are included in the intercomparison, made using seven different systems, summarised in Table 1. As a reference, a climatology is also included in the intercomparison. Most systems assimilate MIPAS ozone observations, though KNMI analyses assimilate SCIAMACHY instead. Apart from the common time period, and (in most cases) the assimilation of MIPAS, we did not impose other standardisation. This was both for reasons of expediency and also to include as many analysis products as possible in the intercomparison. Both CTMs and GCMs are represented, and ozone chemistry may or may not be modelled. If included, it is done either by highly detailed reaction schemes or via a parametrization often known as a Cariolle scheme (e.g., Cariolle and Déqué, 1986; McLinden et al., 2000; McCormack et al., 2004). The Cariolle scheme is a linearisation of ozone photochemistry around an equilibrium state, using parameters derived from a more detailed model.

Analyses are interpolated from their native resolution onto a common grid and then compared to independent ozone data from Halogen Occultation Experiment (HALOE), ozonesondes and TOMS, and to MIPAS. The common grid simplified the task of making the intercomparison, but it also introduced avoidable errors. Section 4.1 quantifies these errors; we do not believe they have much impact on our conclusions.

Most of the analysis systems are focused on the stratosphere, but the scope of the comparison spans from the troposphere to the mesosphere. This is because many of the assimilation systems produce output over the whole vertical range. The quality of the analyses is expected to be poor in the troposphere but it is still useful to quantify and understand the errors in such regions.

This paper introduces the intercomparison project, the method used, the independent data sources, and the anal- ysis systems involved. It outlines many of the initial results and it draws initial conclusions on the various different methods used. There is not scope in this paper for detailed comparisons, such as between different types of chemistry schemes, or between 3-D-Var and 4-D-Var. These are anyway best performed in an experimental setting within a single assimilation system. However, the intercomparison provides a framework under which these results, and their significance, can be assessed by comparison to a variety of other assimilation approaches and systems. These more detailed results will be described in further papers. Most data, figures, and code are publicly available via the project website (http://darc.nerc.ac.uk/asset).

\section{Analyses}

Before describing in detail the analyses and climatologies in the intercomparison, we show examples of the ozone fields at $68 \mathrm{hPa}$ on 31 August 2003 (Fig. 1). Sunlight has started to return to high latitudes after the winter, triggering the depletion of ozone in a ring around the pole (see e.g., WMO, 2003). Sunlight has not yet returned to the pole itself. The ring of higher ozone ( 3 to $5 \mathrm{ppmm}$ ) at about $45^{\circ} \mathrm{S}$ is the remainder of ozone that has descended throughout the SH high latitudes during the winter, from levels higher in the atmosphere where ozone amounts are greater. It is clear that at $68 \mathrm{hPa}$ all the analyses show broadly similar and (from Sect. 5) realistic structures. Compared to the others, the KNMI SCIAMACHY profile analyses have a bias; due to a lack of observations before October they are based principally on the free-running model.

\subsection{ECMWF}

Ozone observations have been assimilated into the operational ECMWF analyses (http://www.ecmwf.int) since April 2002. During 2003, GOME columns and SBUV profiles were assimilated, though in August and September 2003, there was very limited availability of GOME data. MIPAS was assimilated operationally from from 7 October 2003 until 25 March 2004. Here we consider two datasets: (a) the operational analyses and (b) a dataset that includes assimilated MIPAS ozone throughout the July-November period, based on a pre-operational test suite before 7 October, and operational analyses after 7 October (Dethof, 2003a). In all cases, the MIPAS data is version 4.59 of the Near Real Time product. Gross outliers in the MIPAS retrievals are rejected based on a comparison against the background ozone. Variational quality control is also applied (Andersson and Järvinen, 1999).

The GCM in use when the analyses were made had a horizontal resolution of T511 $(\sim 50 \mathrm{~km})$ and 60 levels in the vertical, from the surface up to $0.1 \mathrm{hPa}$. Ozone was advected using a semi-Lagrangian transport scheme. Ozone chemistry 

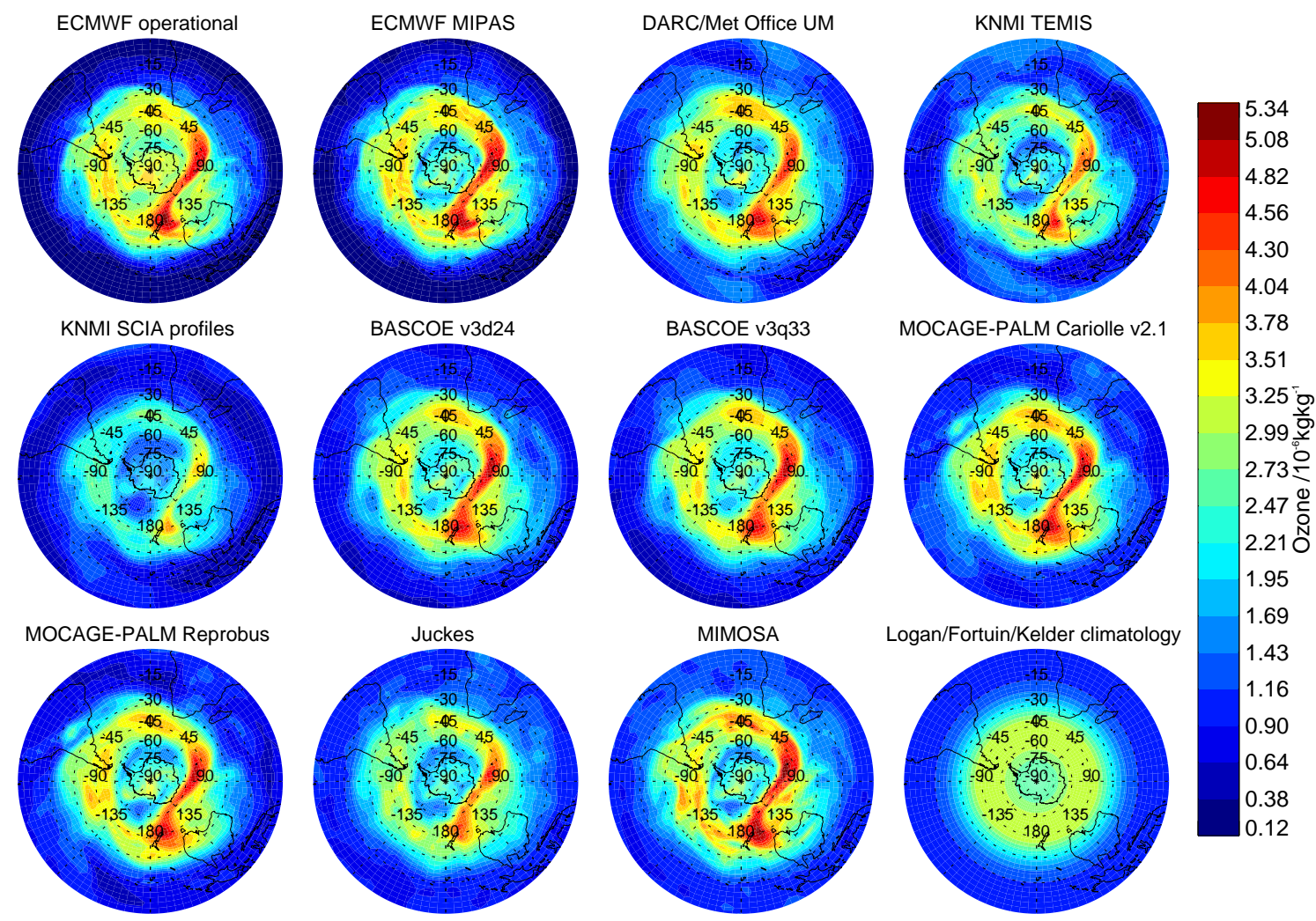

Fig. 1. Ozone (ppmm) at $68 \mathrm{hPa}$ in the southern hemisphere on 31 August 2003, shown on a polar stereographic projection bounded by the equator.

was parametrized with version 1.2 of the Cariolle scheme (Cariolle and Déqué, 1986; Dethof and Hólm, 2004), which includes a description of heterogeneous ozone depletion. Climatological ozone (Fortuin and Langematz, 1995), not prognostic ozone, was used for modelling heating rates.

Data assimilation uses 4D-Var (e.g., Rabier et al., 2000). Ozone is assimilated univariately, but it can still affect the dynamical analyses through the 4D-Var method (e.g., Riishøjgaard, 1996) and through the influence of ozone on the assimilation of temperature radiances. Background error correlations are calculated using an ensemble of analyses (Fisher, 2003); background error variances are flow dependent.

\subsection{DARC/Met Office}

The Met Office NWP system has recently been extended to allow the assimilation of ozone (Jackson and Saunders, 2002; Jackson, 2004) but ozone is not assimilated operationally. Here, MIPAS v4.61 ozone and temperature are assimilated in re-analysis mode, alongside all operational dynamical observations, using a stratosphere/troposphere version of the operational NWP system. The system is that described in Geer et al. (2006b), but with a number of improvements to the
GCM and no assimilation of HIRS (High resolution infrared radiation sounder) channel 9 ozone radiances.

The assimilating GCM has a horizontal resolution of $3.75^{\circ}$ longitude by $2.5^{\circ}$ latitude and 50 levels in the vertical, from the surface to $\sim 0.1 \mathrm{hPa}$. It uses a new dynamical core (Davies et al., 2005) which includes a semiLagrangian transport scheme. This gives a better description of the Brewer-Dobson circulation than that seen in Geer et al. (2006b). Ozone photochemistry is parametrized by v1.0 of the Cariolle and Déqué (1986) scheme. Improving on Geer et al. (2006b), heterogeneous ozone chemistry is now parametrized, using a cold tracer scheme (Eskes et al., 2003). Climatological ozone ( $\mathrm{Li}$ and Shine, 1995), not the prognostic field, is used for modelling heating rates.

Data assimilation uses 3-D-Var (Lorenc et al., 2000). As for ECMWF, ozone is assimilated univariately, but 3-D-Var does not infer dynamical information, so the only effect of ozone on the dynamical analysis is through its influence on temperature radiance assimilation. Background error covariances are uniform for all latitudes and longitudes, and they are based on the ECMWF vertical covariances. As illustrated in Geer et al. (2006b), the MIPAS ozone observations are subject to quality control, but with a lax threshold, so very few observations are rejected. 


\section{$2.3 \mathrm{KNMI}$}

The Royal Netherlands Meteorological Institute (KNMI) operate a CTM (known as TM5) which has been used to assimilate SCIAMACHY ozone data. The CTM uses a subset of 44 of the ECMWF model levels, from the surface to $0.1 \mathrm{hPa}$, on a $3^{\circ}$ longitude by $2^{\circ}$ latitude grid. Data assimilation is done using a sub-optimal Kalman Filter (see e.g., Kalnay, 2003), where the background error variances, but not the correlations, are advected as a tracer. Two different configurations are presented.

The first configuration assimilates total column ozone from SCIAMACHY, retrieved at KNMI using the TOSOMI algorithm (Total Ozone retrieval scheme for SCIAMACHY based on the OMI DOAS algorithm, Eskes et al., 2005b). The CTM is driven by ECMWF operational analyses of winds and temperatures. Ozone photochemistry is parametrized using the LINOZ scheme (McLinden et al., 2000), a variant on Cariolle and Déqué (1986). Heterogeneous chemistry uses a cold tracer scheme. For assimilating total column observations, the vertical error correlations are set proportional to the vertical ozone profile. The system is very similar to that described in Eskes et al. (2003).

The second configuration assimilates ozone profiles (IFE v1.6) from the limb-sounding mode of SCIAMACHY. SCIAMACHY limb profiles are mainly available for October and November 2003; July to September is a free model run apart from a few assimilated profiles in August. The main uncertainty in the SCIAMACHY product is pointing, which has a vertical offset of $1-2 \mathrm{~km}$ (Segers et al., 2005b). All profiles have been shifted in the vertical to get the best match with model forecasts prior to analysis. Ozone chemistry is parametrized using Cariolle and Déqué (1986) v1.0 and a cold-tracer scheme. The CTM is driven by ECMWF short range forecasts at 3 hourly intervals. The system is otherwise similar to that described in Segers et al. (2005a).

\subsection{BASCOE}

The Belgian Assimilation System of Chemical Observations from ENVISAT (BASCOE, http://www.bascoe.oma.be) is a 4D-Var assimilation system descended from that described in Errera and Fonteyn (2001). Studies of the Antarctic and Arctic winter using the CTM of BASCOE can be found in Chabrillat et al. (2006) ${ }^{1}$ and Daerden et al. (2006). MIPAS v4.61 ozone $\left(\mathrm{O}_{3}\right)$, water vapour $\left(\mathrm{H}_{2} \mathrm{O}\right)$, nitric acid $\left(\mathrm{HNO}_{3}\right)$, nitric dioxide $\left(\mathrm{NO}_{2}\right)$, methane $\left(\mathrm{CH}_{4}\right)$ and nitrous oxide $\left(\mathrm{N}_{2} \mathrm{O}\right)$ are assimilated. Observations are subjected to an Optimal Interpolation Quality Check (OIQC, e.g. Gauthier et al., 2003). In practice, the lowest MIPAS ozone ob-

\footnotetext{
${ }^{1}$ Chabrillat, S. H., Van Roozendael, M., Daerden, F., Errera, Q., Hendrick, F., Bonjean, S., Wilms-Grabe, W., Wagner, T., Richter, A., and Fonteyn, D.: Quantitative assessment of 3-D PSCchemistry-transport models by simulation of GOME observations during the Antarctic winter of 2002, in preparation, 2006.
}

servations in the ozone hole are rejected. Observations are also rejected if they fail a check for spurious vertical oscillations in the profile.

The model includes 57 chemical species and 4 types of stratospheric PSC particles (ice; supercooled ternary solution, STS; nitric acid trihydrate, NAT; sulphuric acid tetrahydrate, SAT) with a full description of stratospheric chemistry and microphysics of PSCs. All chemical species are advected and interact through 143 gas-phase reactions, 48 photolysis reactions and 9 heterogeneous reactions. To allow for calculating transport of PSCs, size distributions of each type are discretized using 36 bins from 0.002 to $36 \mu \mathrm{m}$. PSC microphysics is described by the PSCBox scheme (Larsen et al., 2000). In order to improve agreement with MIPAS ozone, $\mathrm{O}_{2}$ photolysis rates were multipled by 1.25 . This version is referred to as v3d24.

Based on early results of this intercomparison, a new version of BASCOE, v3q33, was produced. Among the changes, v3q33 replaces the full PSC calculation by a parametrization that defines (1) surface area density of ice and NAT when their occurrence is possible and (2) the loss of $\mathrm{HNO}_{3}$ and $\mathrm{H}_{2} \mathrm{O}$ due to sedimentation (Chabrillat et al., $2006^{1}$ ). Ice PSCs are supposed to exist in the winter/spring polar regions at any grid point where the temperature is colder than $186 \mathrm{~K}$, and NAT PSCs at any grid point where the temperature is colder than $194 \mathrm{~K}$. The surface area density is set to $10^{-6} \mathrm{~cm}^{2} / \mathrm{cm}^{3}$ in the first case and $10^{-7} \mathrm{~cm}^{2} / \mathrm{cm}^{3}$ in the second. Additionally in $\mathrm{v} 3 \mathrm{q} 33, \mathrm{O}_{2}$ photolysis rates are no longer scaled; this reduces the bias against HALOE but increases it against MIPAS (see Sect. 5.1). Finally, the Arakawa A grid of v3d24 was replaced by a C grid (see e.g., Kalnay, 2003) in v3q33.

The CTM is driven by ECMWF operational analyses of winds and temperatures, and uses a subset of 37 of the ECMWF model levels, from the surface to $0.1 \mathrm{hPa}$, on a $5^{\circ}$ longitude by $3.75^{\circ}$ latitude grid.

Data assimilation is done using 4D-Var. The background error standard deviation is set as $20 \%$ of the background ozone amount. Though there are no off-diagonal elements in the background error covariances (i.e. no vertical or horizontal correlations), information from MIPAS observations is still spread through the observation operator, as in other systems. Here, it averages the 8 grid points surrounding the measurement point, and the relatively broad horizontal resolution of the grid also helps to spread the information.

\subsection{Météo-France/CERFACS}

The Météo-France/CERFACS assimilation system is based upon the 3-D CTM MOCAGE and the PALM software (Massart et al., 2005). MIPAS v4.61 ozone data are assimilated, but not poleward of $80^{\circ}$ of latitude.

The PALM framework is particularly versatile, as both the CTM degree of sophistication (for instance, the number of chemical tracers involved, the physical or chemical 
parametrizations, the horizontal and vertical geometries) and the data assimilation technique can be changed easily; this makes the MOCAGE-PALM system a useful platform for sensitivity studies in chemical data assimilation.

MOCAGE is a flexible tropospheric and stratospheric 3D CTM developed at Météo-France, offering several configurations of varying computational costs. Two separate configurations are examined here. The first uses linear ozone chemistry, with v2.1 of the Cariolle and Déqué (1986) scheme. The second includes a detailed representation of stratospheric and upper tropospheric chemistry, based upon the REPROBUS chemical scheme (Lefèvre et al., 1994), which comprises 55 transients and species and takes into account heterogeneous chemistry on polar stratospheric clouds (Carslaw et al., 1995; Lefèvre et al., 1998). The REPROBUS chemistry version of MOCAGE has already been used for UTLS assimilation studies (Cathala et al., 2003). A more comprehensive version of MOCAGE, with comprehensive tropospheric chemistry, is run daily in operational mode at Météo-France for chemical weather and air quality applications (Dufour et al., 2004, see daily global forecasts at http://www.prevair.org/en)

MOCAGE relies on a semi-Lagrangian advection scheme (Josse et al., 2004). For the experiments presented here, MOCAGE has a $2^{\circ}$ by $2^{\circ}$ horizontal resolution and 47 hybrid sigma/pressure levels extending from the surface up to $5 \mathrm{hPa}$. The meteorological forcings are Météo-France ARPEGE operational meteorological analyses of pressure, winds, temperature and humidity (Courtier et al., 1991), available every $6 \mathrm{~h}$.

Any assimilation algorithm can be seen as a sequence of elementary operations or elementary components that can exchange data (Lagarde et al., 2001). Based on this idea, the CERFACS PALM software (http://www.cerfacs.fr/ $\sim$ palm) manages the dynamic launching of the coupled components (forecast model, algebra operators, I/O of observational data) and the parallel data exchanges. The MOCAGEPALM assimilation system is set up here in a 3-D-FGAT configuration (3-D First Guess at Assimilation Time, Fisher and Andersson, 2001). As a first approximation, background error standard deviations are prescribed as $20 \%$ of the background ozone amount. In order to spread assimilation increments spatially, horizontal background error correlations are modelled using a generalized diffusion operator (Weaver and Courtier, 2001), with a length-scale of $4^{\circ}$; no vertical background error correlations are considered.

\subsection{MIMOSA}

MIMOSA (Modèle Isentrope de transport Mésoéchelle de l'Ozone Stratosphérique par Advection) is a CTM driven by ECMWF operational winds and temperatures (Fierli et al., 2002). MIPAS v4.61 ozone data are assimilated. There is no quality control; all observations are included. There are 16 isentropic levels from $335 \mathrm{~K}$ to $1650 \mathrm{~K}$, approximately span- ning the stratosphere $(\sim 200 \mathrm{hPa}$ to $\sim 1 \mathrm{hPa})$ and a $1^{\circ}$ by $1^{\circ}$ latitude-longitude grid. Advection is semi-Lagrangian. The model includes neither ozone chemistry nor cross-isentropic transport.

Data assimilation is done using a sub-optimal Kalman Filter with advected background error variances, and uses the Physical Space Assimilation System method (PSAS, e.g. Kalnay, 2003). Background error correlations are flow dependent and anisotropic, specified in terms of distance and the potential vorticity (PV) field. The model error covariance $(Q)$ is diagonal, and proportional to the ozone amount, $x$, e.g. $Q=(q x)^{2}$ where $q=0.024 \mathrm{day}^{-1}$ and has been tuned using $\chi^{2}$ tests.

ECMWF operational temperature and pressure fields are used to interpolate these isentropic analyses onto pressure levels for this study.

\subsection{Juckes}

These are analyses produced by a direct inversion method (Juckes, 2006a,b), which assimilates months of MIPAS v4.61 ozone data by making a single iterative solution. The physical constraint is based on an isentropic transport equation. Rather than discretising the predictive equations (which would give a CTM), the product of these equations with their adjoint is discretised. The resulting self-adjoint system of equations is solved with a multigrid relaxation algorithm. This is equivalent to solving the Kalman Smoother (e.g. Rodgers, 2000) with fully advected background error covariances. However, this technique avoids the need to represent the background error covariance matrix explicitly.

Ozone transport is driven by ECMWF operational winds and temperatures, on 13 isentropic levels from $380 \mathrm{~K}$ to $3000 \mathrm{~K}$. In the horizontal, a binary thinned latitude-longitude spherical grid is used, giving approximately $2^{\circ}$ by $2^{\circ}$ resolution. The model error covariance $(Q)$ is diagonal, with a constant value of $0.02 \mathrm{ppmv}^{2} / \mathrm{day}^{2}$. The model includes neither ozone chemistry nor cross-isentropic transport. As for MIMOSA, ECMWF pressure and temperature fields are used for interpolation onto pressure levels in this study.

\subsection{Climatology}

To contrast with the assimilated ozone fields, we include a climatology-derived product in the comparison. As a minimum, we would expect the analyses to do better than climatology. We combine the Logan (1999) tropospheric ozone climatology with the Fortuin and Kelder (1998) stratospheric ozone climatology. In each case, the climatologies are resolved on a monthly basis.

The Logan (1999) climatology uses ozonesonde, surface in-situ data and the TOMS/Stratospheric Aerosol and Gas Experiment (SAGE) tropospheric residual, to produce a partly 3-D and partly 2-D climatology on 13 levels from $1000 \mathrm{hPa}$ to $100 \mathrm{hPa}$, covering latitudes from $89^{\circ} \mathrm{S}$ to $89^{\circ} \mathrm{N}$. 

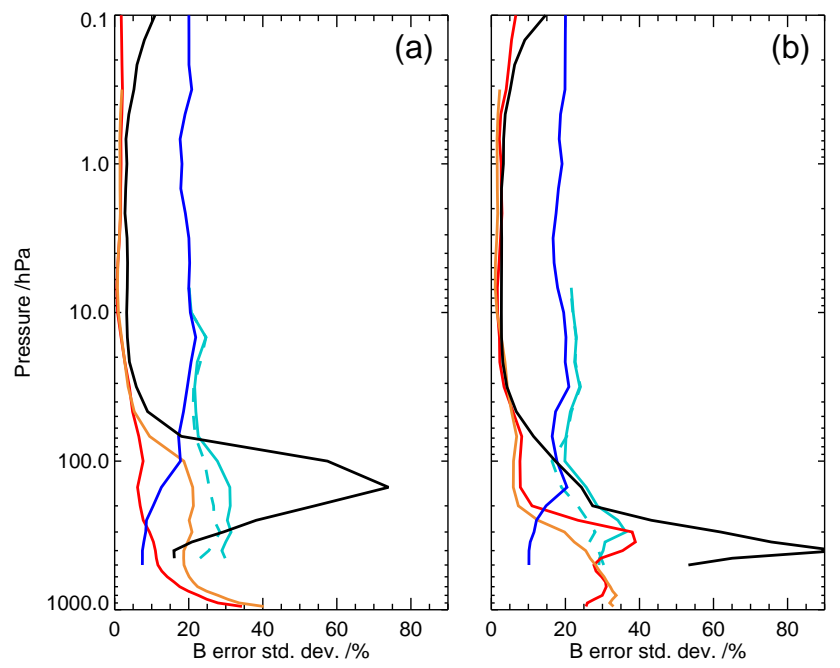

Fig. 2. Standard deviation of ozone background error, given as a percentage relative to climatological ozone, averaged for the period 7 October 2003 to 31 October 2003 in the regions (a) $30^{\circ} \mathrm{S}$ to $30^{\circ} \mathrm{N}$ and (b) $60^{\circ} \mathrm{S}$ to $90^{\circ} \mathrm{S}$, for the analysis systems of ECMWF, DARC, BASCOE and MOCAGE-PALM (see key in Fig. 3). MIPAS error standard deviations, averaged for the same region and time period, are shown by the black line.

The Fortuin and Kelder (1998) climatology uses ozonesondes, SBUV and TOMS total ozone, from 1980 to 1991, to produce a 2-D (latitude-pressure) climatology with 19 levels from $1000 \mathrm{hPa}$ to $0.3 \mathrm{hPa}$ and covering latitudes from $80^{\circ} \mathrm{S}$ to $80^{\circ} \mathrm{N}$.

An ozone field was created on the intercomparison common grid, daily at $00 \mathrm{Z}$ and $12 \mathrm{Z}$, by interpolating the climatologies linearly in time, and treating the climatologies as representative of the 15th of each month. Beyond the northern and southern limits of the climatologies, horizontal extrapolation was done at constant value. Logan (1999) values were taken for levels at $150 \mathrm{hPa}$ and below, and Fortuin and Kelder (1998) above, up to $0.3 \mathrm{hPa}$. Figure 1 shows that this results in a zonal distribution which, as expected, does not represent the synoptic features in the ozone field.

\subsection{Comparison of ozone background errors}

The background error covariance matrix (e.g., Kalnay, 2003) is important in determining the weight given to observations in data assimilation. In general, at the observation point, more weight is given to the model as the background error standard deviation becomes smaller compared to the observation error standard deviation. However, the spreading of information away from the observation point is determined by the background error correlations, any observation error correlations (not usually considered), and the observation operator. Here, only the DARC and ECMWF systems include vertical correlations in the background errors. The general

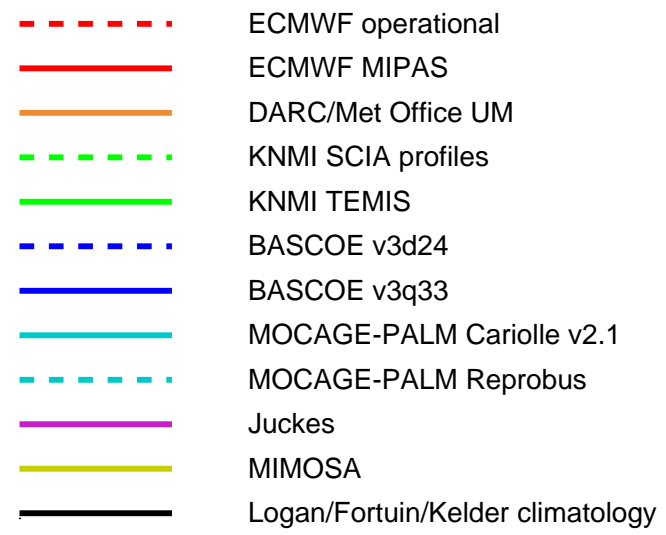

Fig. 3. Key to the analyses. Typically only a subset of these are shown in any one figure.

impact of observations on the system will also depend on how many observations are rejected by quality control.

We examine the background error standard deviation (i.e. the square root of the diagonal of the background error covariance matrix) from a number of the analysis systems, and compare it to the MIPAS ozone observation error standard deviation (Fig. 2). In each case these have been normalised by the climatological ozone amount (see Sect. 4 for the method). The comparison is done to illustrate the varied approaches to background error modelling, and to give some indication of the weight assigned to observations in the different systems. As already noted, however, many other factors affect the observations' weight in the final analysis.

Figure 2 shows large differences in the ozone background error standard deviations assumed in the assimilation systems. In the mid and upper stratosphere (levels above $30 \mathrm{hPa}$ ), DARC and ECMWF background error standard deviations are less than $5 \%$ of the ozone field. These are ultimately derived from an ensemble of analyses (Fisher, 2003); the small standard deviations in the upper stratosphere and mesosphere are most likely due to the strong control of the ozone field by parametrized ozone photochemistry schemes at these levels. The BASCOE and (to $5 \mathrm{hPa}$ ) MétéoFrance/CERFACS systems have background error standard deviations of typically $20 \%$, based on ad-hoc methods. At these levels the DARC and ECMWF analyses are likely to give less weight to observations. MIPAS observation errors are markedly larger at the tropical tropopause, and all the systems are likely to give relatively lower weight to MIPAS observations here than in the rest of the stratosphere.

The specification of background errors is known to be one of the most difficult parts of any assimilation system. From Fig. 2 and the details given earlier, we see that ozone assimilation systems use very varied and often ad-hoc approaches to modelling background error covariances. Despite this, we later find that the quality of the analyses is often similar: any 
differences coming from the background errors are too small to be identified in an intercomparison. This is certainly an area where more studies are needed.

\section{Ozone observations}

\subsection{MIPAS}

MIPAS observations are used in two ways in this paper. First, MIPAS ozone observations have been assimilated into all the analyses, except those from KNMI, which assimilated SCIAMACHY instead. The exact set of MIPAS observations included in each system will vary, depending upon the quality control procedures used. Second, in order to calculate statistics for the intercomparison, we have compared a fixed set of MIPAS observations to all the analyses including those from KNMI.

MIPAS is an interferometer for measuring infrared emissions from the atmospheric limb (Fischer and Oelhaf, 1996). MIPAS operational data are available between July 2002 and March 2004, after which instrument problems meant it could only be used on an occasional basis. The operational measurements were made along 17 discrete lines-of-sight in the reverse of the flight direction of ENVISAT, with tangent heights between $8 \mathrm{~km}$ and $68 \mathrm{~km}$. The vertical resolution was $\sim 3 \mathrm{~km}$ and the horizontal resolution was $\sim 300 \mathrm{~km}$ along the line of sight. ENVISAT follows a sun-synchronous polar orbit, allowing MIPAS to sample globally, and to produce up to $\sim 1000$ atmospheric profiles per day. Coverage is quite uniform in time and there are only minor variations with latitude (see Fig. 4).

From the infrared spectra, ESA retrieved profiles of pressure, temperature, ozone, water vapour, $\mathrm{HNO}_{3}, \mathrm{NO}_{2}, \mathrm{CH}_{4}$ and $\mathrm{N}_{2} \mathrm{O}$ at up to 17 tangent points (ESA, 2004; Raspollini et al., 2006). MIPAS version 4.61 data, reprocessed offline, is used throughout this work, except in the ECMWF assimilation runs, where the Near Real Time v4.59 product was used. The differences between v4.59 and v4.61 processors are minor.

MIPAS ozone appears unbiased when compared to independent data except in the lower stratosphere where a small positive bias has been noted (Dethof, 2003a,b, 2004; Fischer and Oelhaf, 2004; Wargan et al., 2005; Geer et al., 2006b). However, a comparison against ozonesondes using the MIPAS averaging kernels, but only a limited number of colocations, identified no bias (Migliorini et al., 2004). In Sect. 5.3 we find a positive bias of order $5 \%$ in the upper stratosphere with respect to HALOE, increasing to roughly $10 \%$ with respect to sonde and HALOE in the lower stratosphere. The official MIPAS validation papers are currently in preparation.

Typically, assimilation systems produce observation minus first guess (O-F) statistics that are used for monitoring biases between the observations and the models, and checking that statistical assumptions are valid in the assimilation

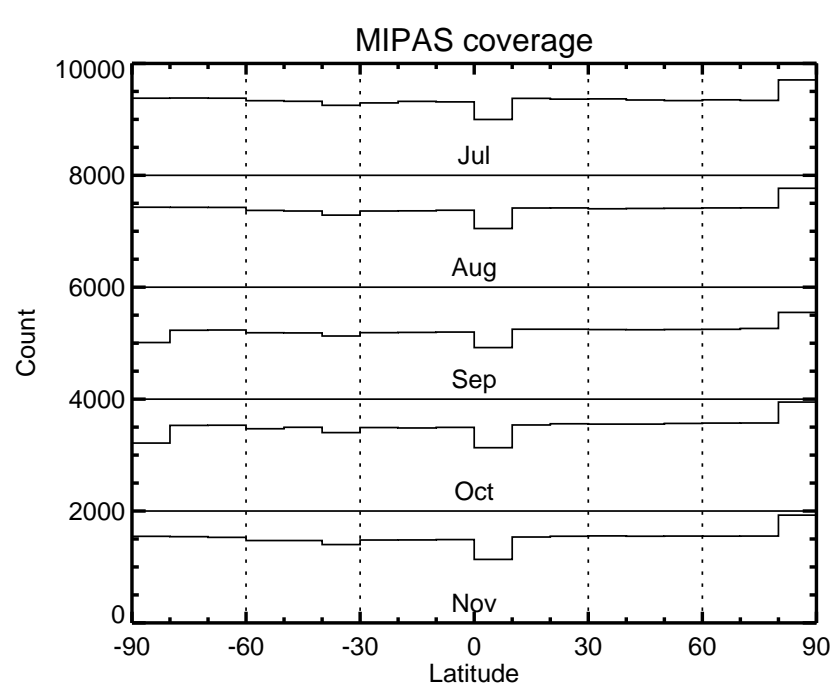

Fig. 4. Number of MIPAS profiles used for validation, by latitude (in $10^{\circ}$ bins) and by month, for July to November 2003 . Histograms for different months have been staggered by an interval of 2000 counts.

algorithm (e.g., Talagrand, 2003; S̆tajner et al., 2004). We did not use the O-F statistics produced by the assimilation systems themselves but instead calculated statistics from a comparison between the common-gridded analyses and a fixed set of MIPAS observations. This was done to avoid reading a plethora of different file formats, to ensure that a fixed set of observations was used, and to be able to calculate statistics for those analyses which did not include MIPAS observations. Section 4.1 quantifies the errors resulting from the use of the common grid. The fixed set of MIPAS observations included all those supplied in the ESA data files except those that failed screening criteria developed during data assimilation experiments at DARC (Lahoz et al., 2006).

To calculate statistics of the difference between analysis and MIPAS, the MIPAS retrievals are treated as point measurements and the analyses are interpolated to the MIPAS retrieval points linearly in $\ln (P)$ in the vertical. The paired differences are then binned to the nearest pressure level on the intercomparison grid. It is well known that comparison in terms of radiances, or the use of averaging kernels (Rodgers, 2000; Migliorini et al., 2004), produces a better representation of the information content of the retrievals; these methods are increasingly used in calibration and validation activities. But here, no assimilation system uses MIPAS radiances or an averaging kernel representation, so it is the bias in MIPAS retrievals, treated as a point values, that is important.

\subsection{Ozonesondes}

Ozonesondes are used as independent data to validate the analyses. Profiles have been obtained from the World Ozone and Ultraviolet Radiation Data Centre (WOUDC, 


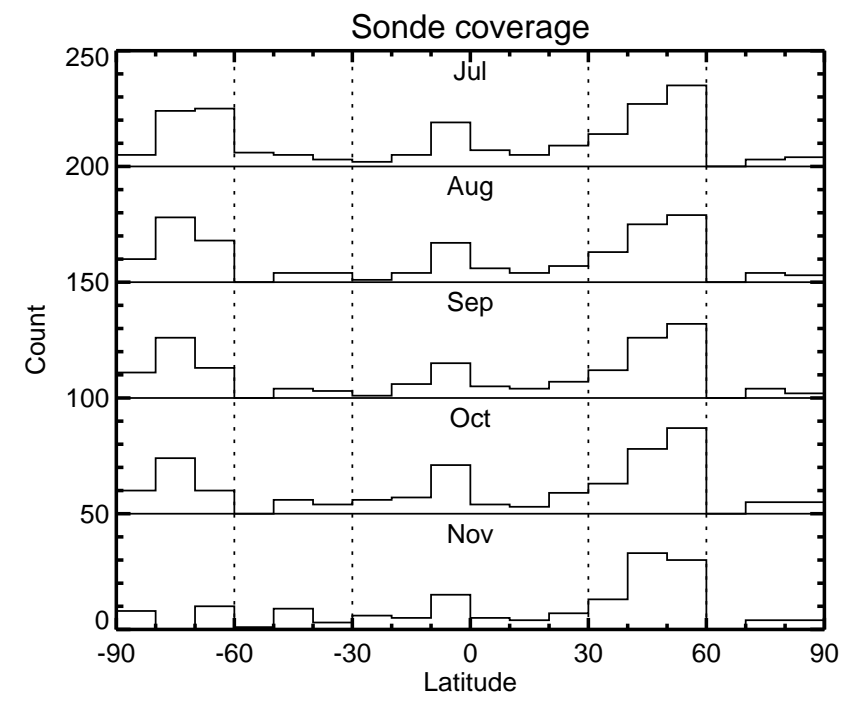

Fig. 5. Number of ozonesonde profiles used for validation, by latitude (in $10^{\circ}$ bins) and by month, for July to November 2003 . Histograms for different months have been staggered by an interval of 50 counts.

http://www.woudc.org/), Southern Hemisphere Additional Ozonesondes project (SHADOZ, http://croc.gsfc.nasa.gov/ shadoz/, Thompson et al., 2003a,b) and the Network for the Detection of Stratospheric Change (NDSC, http://www. ndsc.ncep.noaa.gov/). We use ozonesonde ascents from 42 locations, not including the Indian stations, and comprising mostly Electrochemical Concentration Cell (ECC) types, with five locations using Carbon-Iodide sondes and one location using Brewer-Mast sondes. We approach this dataset in the knowledge that it may be somewhat heterogeneous, both in the sonde types used, but also in the correction factors applied to the data, and in the operating procedures at each site. See Komhyr et al. (1995) and Thompson et al. (2003a) for more discussion of the importance of these techniques and procedures. However, we believe this heterogeneity is worth accepting in order to gain the widest global coverage. The number of sonde ascents available to this intercomparison, and their latitudinal and temporal coverage, are summarised in Fig. 5. Sondes typically make measurements from the surface to around the $10 \mathrm{hPa}$ level.

Total error for ECC sondes is estimated to be within $-7 \%$ to $+17 \%$ in the upper troposphere, $\pm 5 \%$ in the lower stratosphere up to $10 \mathrm{hPa}$ and $-14 \%$ to $+6 \%$ at $4 \mathrm{hPa}$ (Komhyr et al., 1995). Errors are higher in the presence of steep ozone gradients and where ozone amounts are low.

In order to compare sonde profiles, with a relatively high vertical resolution, to the analyses on the intercomparison common grid, the sonde profiles are averaged over a layer bounded by the half-way points (calculated linearly) between the common pressure levels. For example, analyses at $100 \mathrm{hPa}$ are compared to the mean of any ozonesonde pro-

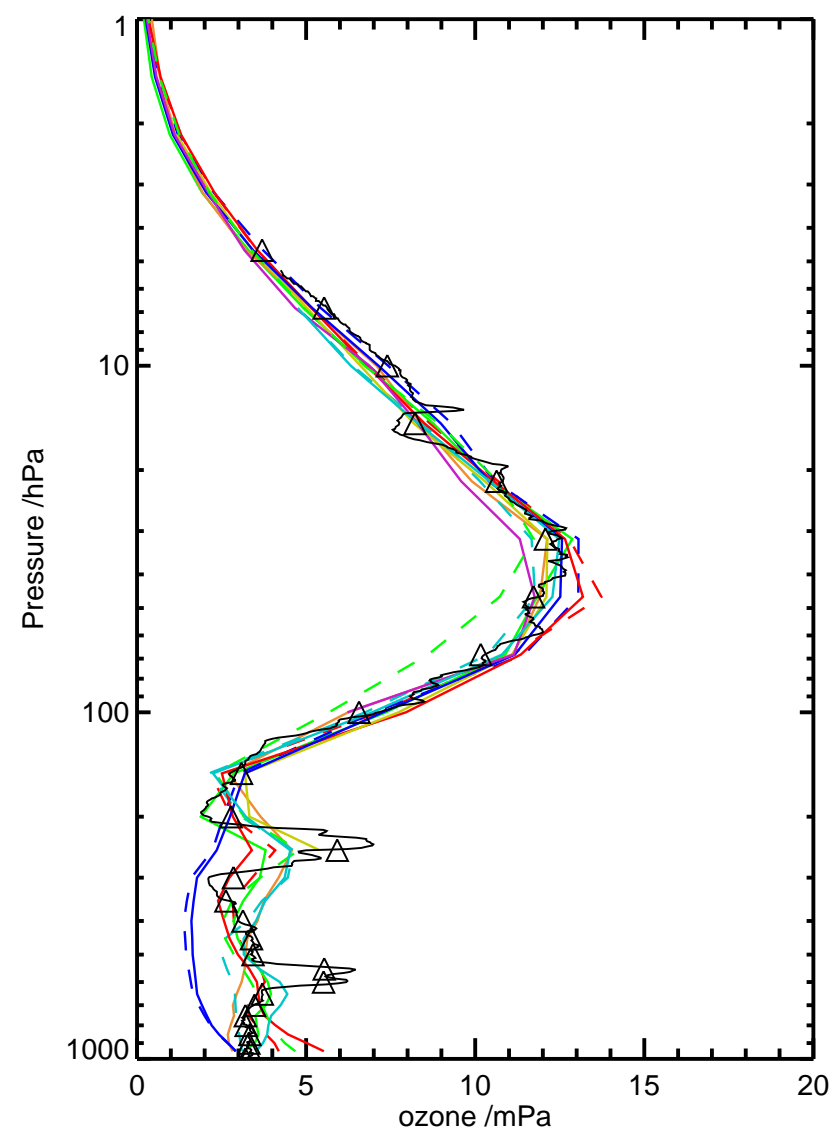

Fig. 6. Example of comparison between sonde ozone at full resolution (black line), layer-averaged (black triangles) and the analyses (key in Fig. 3) at 11:36 UTC on 24 September 2003 at Legionowo $\left(21.0^{\circ} \mathrm{E}, 52.4^{\circ} \mathrm{N}\right)$.

file points between $125 \mathrm{hPa}$ and $84 \mathrm{hPa}$. Especially within the polar vortex, sondes may drift long distances during their ascent, but tracking information is not always supplied. We disregard the horizontal movement of sondes and assign the measurement position as the launch longitude and latitude.

Figure 6 gives an example of the intercomparison, showing both the full-resolution sonde profile and the layeraverages used to calculate statistics, alongside a number of different analyses. We will return to this figure in Sect. 5.5.

\subsection{HALOE}

HALOE (Russell et al., 1993) uses solar occultation to derive atmospheric constituent profiles. HALOE is used here as independent data for validation. Figure 7 shows the coverage available. The nature of the solar occultation technique makes the data sparse in time and space, with about 15 observations per day at each of two latitudes. The horizontal resolution is $495 \mathrm{~km}$ along the orbital track and the vertical resolution is about $2.5 \mathrm{~km}$. 
We use an updated version 19 product, screened for cloud using the algorithm of Hervig and McHugh (1999), and available from the HALOE website (http://haloedata.larc. nasa.gov/). We found that, compared to the previously available version 19, the one with cloud screening substantially improved the quality of results in this intercomparison around the tropical tropopause. Aside from the cloud screening, version 19 ozone retrievals are nearly identical to those of v18, and above the $120 \mathrm{hPa}$ level they agree with ozonesonde data to within 10\% (Bhatt et al., 1999). Below this level, profiles can be seriously affected by the presence of aerosols and cirrus clouds.

HALOE profiles are supplied on 271 levels with very close vertical spacing, but vertical variation is smooth due to the much broader vertical resolution of the instrument. Hence, to compare to the analyses on common pressure levels, HALOE is simply interpolated between the nearest two of the 271 levels. Longitudes and latitudes vary with height in HALOE profiles but for this comparison, those at $10 \mathrm{hPa}$ are taken to be representative of all levels.

\subsection{TOMS}

The Total Ozone Mapping Spectrometer (TOMS) measures backscattered ultraviolet radiances with high horizontal resolution $(38 \mathrm{~km}$ by $38 \mathrm{~km})$ and daily near-global coverage. There are small gaps between orbital coverage bands near the equator. During the intercomparison period, due to the lack of sunlight at very high latitudes, there is no data in July, August and September in the southern high latitudes; the same for October and November in the north. TOMS is not assimilated in any of the analyses evaluated here.

We use version 8 of the level 3 total column ozone product, which is a daily composite of binned observations. Version 8 has partial corrections for calibration problems in the post-2000 TOMS data from the Earth Probe satellite, and improved retrievals under extreme conditions (high observation angles, in the Antarctic, aerosol loading) compared to v7 (McPeters, personal communication, 2004). A full validation of TOMS v8 has not yet been published, but v7 uncertainties were estimated as about $2 \%$ for the random errors, $3 \%$ for the absolute errors and somewhat more at high latitudes due to the higher zenith angle (McPeters et al., 1998).

\section{Method}

All analyses were interpolated from their native resolutions onto a common grid. This was done to make the intercomparison task easier, but with the knowledge that it would introduce a small extra source of error, quantified in Sect. 4.1.

The resolution of the common grid was determined by the need to minimise storage requirements whilst not losing important geophysical variability in time or space, and so minimising colocation error when comparing with independent

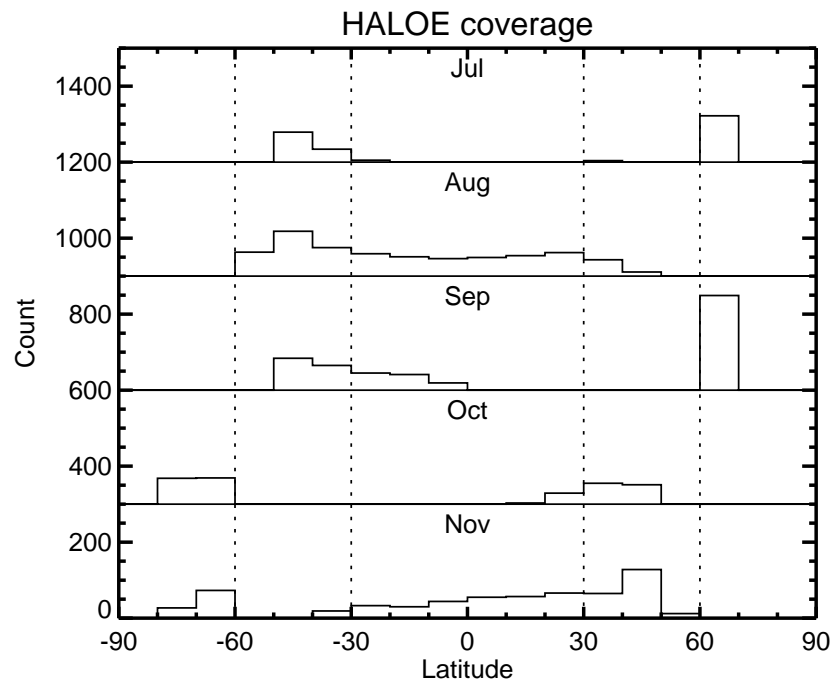

Fig. 7. Number of HALOE profiles used for validation, by latitude (in $10^{\circ}$ bins) and by month, for July to November 2003. Histograms for different months have been staggered by an interval of 300 counts.

data. Based on the results of sensitivity tests (Sect. 4.1), the choice of a $3.75^{\circ}$ longitude by $2.5^{\circ}$ latitude grid, 37 fixed pressure levels, and twice daily analyses (00Z and $12 \mathrm{Z})$ appears to be a reasonable compromise. Pressure levels are 6 per decade between $0.1 \mathrm{hPa}$ and $100 \mathrm{hPa}$ (as used on the Upper Atmosphere Research Satellite (UARS) project). Below this, there are levels at $150,200 \mathrm{hPa}$, and so on every $50 \mathrm{hPa}$ down to $1000 \mathrm{hPa}$.

All comparisons against independent data, except those against TOMS (see Sect. 4.1), were made using analyses on the common grid. All vertical interpolations were done linearly in $\ln (P)$ (where $P$ is pressure) and all horizontal interpolation, bilinearly in longitude and latitude.

Statistics were built up from the difference between analyses and observations. In this paper, statistics were binned in the regions referred to here as the southern and northern high latitudes $\left(90^{\circ} \mathrm{S}\right.$ to $60^{\circ} \mathrm{S}$ and $60^{\circ} \mathrm{N}$ to $90^{\circ} \mathrm{N}$, respectively), the southern and northern midlatitudes $\left(60^{\circ} \mathrm{S}\right.$ to $30^{\circ} \mathrm{S}$ and $30^{\circ} \mathrm{N}$ to $60^{\circ} \mathrm{N}$ respectively) and the tropics $\left(30^{\circ} \mathrm{S}\right.$ to $\left.30^{\circ} \mathrm{N}\right)$. Statistics were binned monthly; also for the entire period 18 August 2003 to 30 November 2003 (before 18 August 2003, the DARC analyses were not adequately spun up).

Ozone amounts vary by many orders of magnitude through the atmosphere. Units of partial pressure emphasise the UTLS; units of mixing ratio emphasise the mid and upper stratosphere. In order to give approximately equal weight through the atmosphere, statistics were normalised with respect to climatology, and displayed as a percentage. As an example, for a particular bin (e.g. July in the tropics at $100 \mathrm{hPa}$ ), where $i$ runs over all $n$ observations in this bin, the percentage mean difference $d$, between analysis interpolated 


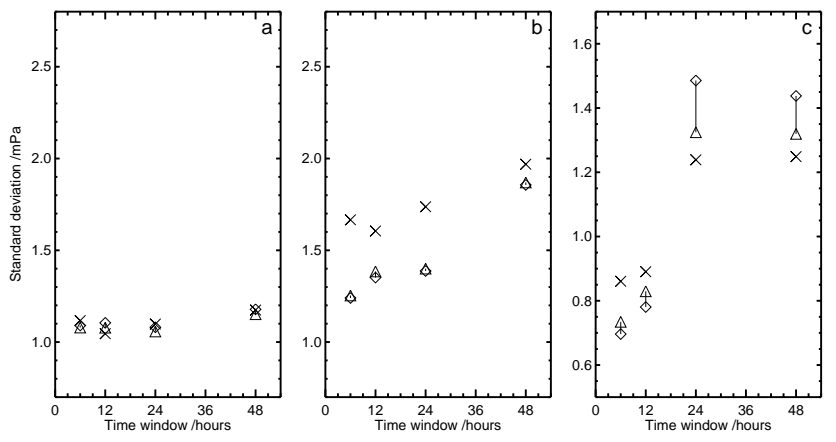

Fig. 8. Effect of varying horizontal and temporal resolution in comparisons between analysed and sonde ozone. The figure shows standard deviation of (analysis - sonde) for 8 October 2003 to 28 November 2003 for: (a) $30^{\circ} \mathrm{S}$ to $30^{\circ} \mathrm{N}$ at $32 \mathrm{hPa}$ (b) $60^{\circ} \mathrm{S}$ to $90^{\circ} \mathrm{S}$ at $32 \mathrm{hPa}$ and (c) $30^{\circ} \mathrm{N}$ to $60^{\circ} \mathrm{N}$ at $200 \mathrm{hPa}$. Crosses represent DARC analyses at $3.75^{\circ}$ by $2.5^{\circ}$ resolution. Diamonds represent ECMWF operational analyses reduced to Gaussian N80 resolution (approximately $1.125^{\circ}$ by $1.125^{\circ}$ ). These are joined by a line to triangles representing ECMWF operational analyses reduced to $3.75^{\circ}$ by $2.5^{\circ}$ resolution.

to the observation positions $\left(A_{i}\right)$ and observations $\left(I_{i}\right)$, would be calculated as

$d=100 \times \frac{\frac{1}{n} \sum_{i}\left(A_{i}-I_{i}\right)}{c}$,

where $c$ is the mean of the Logan/Fortuin/Kelder climatology at this level, for this month, and for this region (e.g. the tropics, $30^{\circ} \mathrm{S}$ to $30^{\circ} \mathrm{N}$ ). This climatology does not go above $0.3 \mathrm{hPa}$, so at the top levels $(0.21,0.15$ and $0.1 \mathrm{hPa})$ we use mean ozone from the BASCOE v3q33 run instead. This particular approach to normalisation was chosen to reduce the influence of very small ozone amounts on the percentage statistics. If a formulation is chosen that includes $I_{i}$ in the denominator, $d$ can show very large percentage values at the tropical tropopause and in the ozone hole.

\subsection{Sensitivity tests}

We investigated the effect of the horizontal and temporal grid resolution on the statistics of $\left(A_{i}-I_{i}\right)$, by varying the time and space resolution of the ECMWF and DARC analyses in comparisons to independent data. As previously described, the intercomparison only considers analyses at $00 \mathrm{Z}$ and $12 \mathrm{Z}$; hence independent data colocations are found within a time window of $12 \mathrm{~h}$. We found that changing the spatial or temporal resolution of the common grid had very little effect on the mean differences between analysis and sonde. However, the standard deviations were affected in some regions and Fig. 8 shows results for four selected time windows: 6, 12,24 and $48 \mathrm{~h}$. We first consider the tropical stratosphere (Fig. 8a), where changing the temporal and horizontal resolution makes very little difference, and the horizontal and
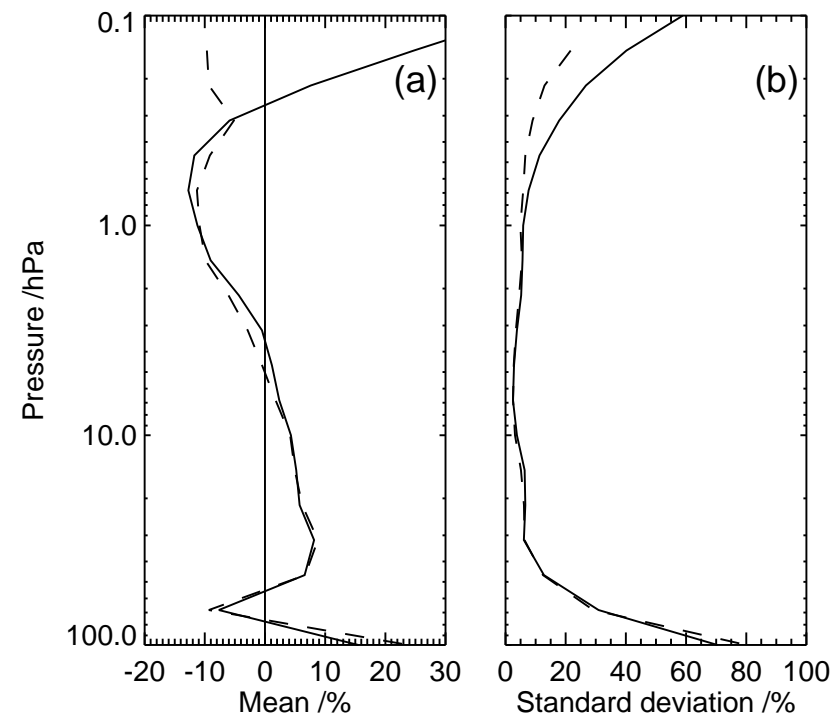

Fig. 9. BASCOE - HALOE ozone (a) bias and (b) standard deviation, normalised by climatology, calculated with a $12 \mathrm{~h}$ time window on the intercomparison grid (solid) and from the original model grid and with a time mismatch of less than $15 \mathrm{~min}$ (dashed). The averaging period is 18 August 2003 to 30 November 2003 and the region is $30^{\circ} \mathrm{S}$ to $30^{\circ} \mathrm{N}$.

temporal variability of ozone appears to be fairly small. The main regions where the temporal and spatial resolution are important are the polar stratosphere (e.g. Fig. 8b) and the midlatitude UTLS (e.g. Fig. 8c). Here, time windows longer than $12 \mathrm{~h}$ appear to increase standard deviations quite considerably. Increased spatial resolution is unimportant in the polar regions, but does have a small effect in the UTLS. Degrading spatial resolution further to that of the BASCOE analyses $\left(5^{\circ}\right.$ by $\left.3.75^{\circ}\right)$ made essentially no difference, and the results are not shown. Hence, it is the time resolution, rather than the horizontal resolution, that limits the accuracy of the intercomparison. The $12 \mathrm{~h}$ time window appears a reasonable compromise.

In the mesosphere, however, there is a strong diurnal cycle in ozone (Sect. 5.8). Figure 9 examines the effect of this on the statistics of (BASCOE - HALOE) ozone for the tropical region. Results at other latitudes are similar. Only the BAS$\mathrm{COE}$ analyses simulate a diurnal cycle. In a special run of the assimilation system, profiles were generated at HALOE observation locations at the nearest model timestep, giving a maximum time mismatch of $15 \mathrm{~min}$. Statistics generated using a $12 \mathrm{~h}$ time window are substantially different above $0.5 \mathrm{hPa}$, indicating the effect of the diurnal cycle. Hence in this work we do not show MIPAS or HALOE statistics above the $0.5 \mathrm{hPa}$ level.

The influence of vertical interpolation on the statistics is more complicated. In the case of TOMS, experiments showed that going from the 50 levels of the DARC analyses 
to the 37 common levels caused a bias in total column calculations of between 3 DU and 7 DU. Hence, ozone columns were calculated for all analyses from their original vertical resolution. Ozonesondes and HALOE have a dense vertical spacing, even if in the case of HALOE the actual resolution is much lower. Ozonesonde measurements were binned onto the common levels; HALOE was interpolated. In neither of these cases do we expect large problems with vertical representativeness.

It is in the comparisons with MIPAS that issues of vertical representation and interpolation are most serious. Interpolation errors can be large where the field being interpolated has extrema or sharp kinks; in ozone profiles the sharp transition at the tropical tropopause between very low tropospheric ozone values and much higher stratospheric values is one of the most severe. To calculate statistics of (analysis - MIPAS) in this study, the analyses are interpolated from the intercomparison common grid to the MIPAS retrieval points. What was the loss of accuracy compared to statistics calculated by interpolating directly from the analyses on their original model levels? This is likely to have been a more accurate approach. As an example, Fig. 10 shows the mean and standard deviation of (ECMWF - MIPAS) for the tropical region, calculated by these two different methods. Compared to using full resolution analyses, the common grid changes MIPAS biases versus ECMWF by up to $7 \%$ near the tropical tropopause (at $100 \mathrm{hPa}$ and $68 \mathrm{hPa}$ ). A similar change is found at the midlatitude tropopause at $100 \mathrm{hPa}$ (not shown), but elsewhere the effect of the common grid is less than $2 \%$. The common grid has virtually no impact on the standard deviations.

It is to be acknowledged that the approach used in this paper for comparisons to independent data is not ideal. Improvements could have been made if the statistics in Eq. (1) were calculated in observation space. However, our approach saved effort and allowed flexibility in the calculation of statistics. Aside from MIPAS comparisons at the tropopause, it introduced few errors.

\section{Results}

This section first gives an overview of the results of the intercomparison, by examining mean (Sect. 5.1) and standard deviation (Sect. 5.2) of differences compared to ozonesonde, HALOE and MIPAS. We then examine MIPAS calibration (Sect. 5.3) and compare the analyses to TOMS (Sect. 5.4). We then examine in more detail the troposphere (Sect. 5.5), tropical tropopause (Sect. 5.6), ozone hole (Sect. 5.7) and the upper stratosphere and mesosphere (Sect. 5.8).

\subsection{Biases}

Figures 11, 12 and 13 show respectively the biases against HALOE, sonde and MIPAS, for the period 18 August 2003 to
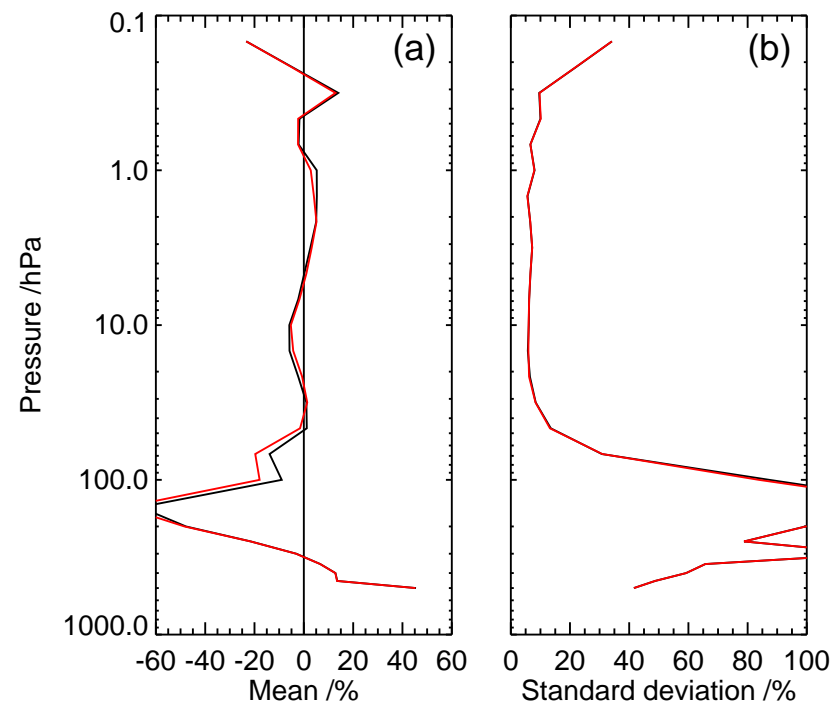

Fig. 10. Effect of different vertical interpolation strategies: (a) Mean and (b) standard deviation of (ECMWF - MIPAS), normalised by climatology. The strategies were to interpolate ECMWF to MIPAS from the original 60 model levels (red), and from the common grid (black). The averaging period is 18 August 2003 to 30 November 2003 and the region is $30^{\circ} \mathrm{S}$ to $30^{\circ} \mathrm{N}$.

30 November 2003, normalised by climatology (see Sect. 4). Indicated at the top of the figure is the number of profiles on which the statistics are based. Statistics are only plotted at a particular level if the number of colocations with data available is at least $50 \%$ (25\% for MIPAS) of the total number of profiles. For example, less than half of sonde ascents reach the $10 \mathrm{hPa}$ level in the northern hemisphere $(\mathrm{NH})$ high latitudes in Fig. 12, so to avoid unrepresentative results, this level is not plotted. Comparisons are not done above $0.5 \mathrm{hPa}$, because of the diurnal cycle in ozone.

For most of the stratosphere and mesosphere above $50 \mathrm{hPa}$, biases between the analyses and HALOE, sonde and MIPAS are between $-10 \%$ and $10 \%$. In the upper stratosphere and mesosphere the ECMWF analyses have biases of up to $20 \%$ in magnitude; DARC and KNMI TEMIS have biases of up to $40 \%$. Section 5.8 shows these biases are caused by problems with the linear chemistry schemes used in the models.

In the lower stratosphere (LS, $100 \mathrm{hPa}$ to $50 \mathrm{hPa}$ ), analyses are biased typically $10 \%$ to $15 \%$ high compared to sonde and HALOE, but some analyses reach $50 \%$ at $100 \mathrm{hPa}$ in the tropics. Biases are typically smaller against MIPAS, reflecting a small $(\sim 10 \%)$ positive bias between MIPAS and the independent data at these levels (Sect. 5.3). There are big variations between different analyses in the lower stratosphere in the SH high latitudes, reflecting the analyses' differing success in capturing the ozone hole (Sect. 5.7) and near the tropical tropopause, associated with both poorly-simulated transport, and a degradation in the quality of the assimilated observa- 

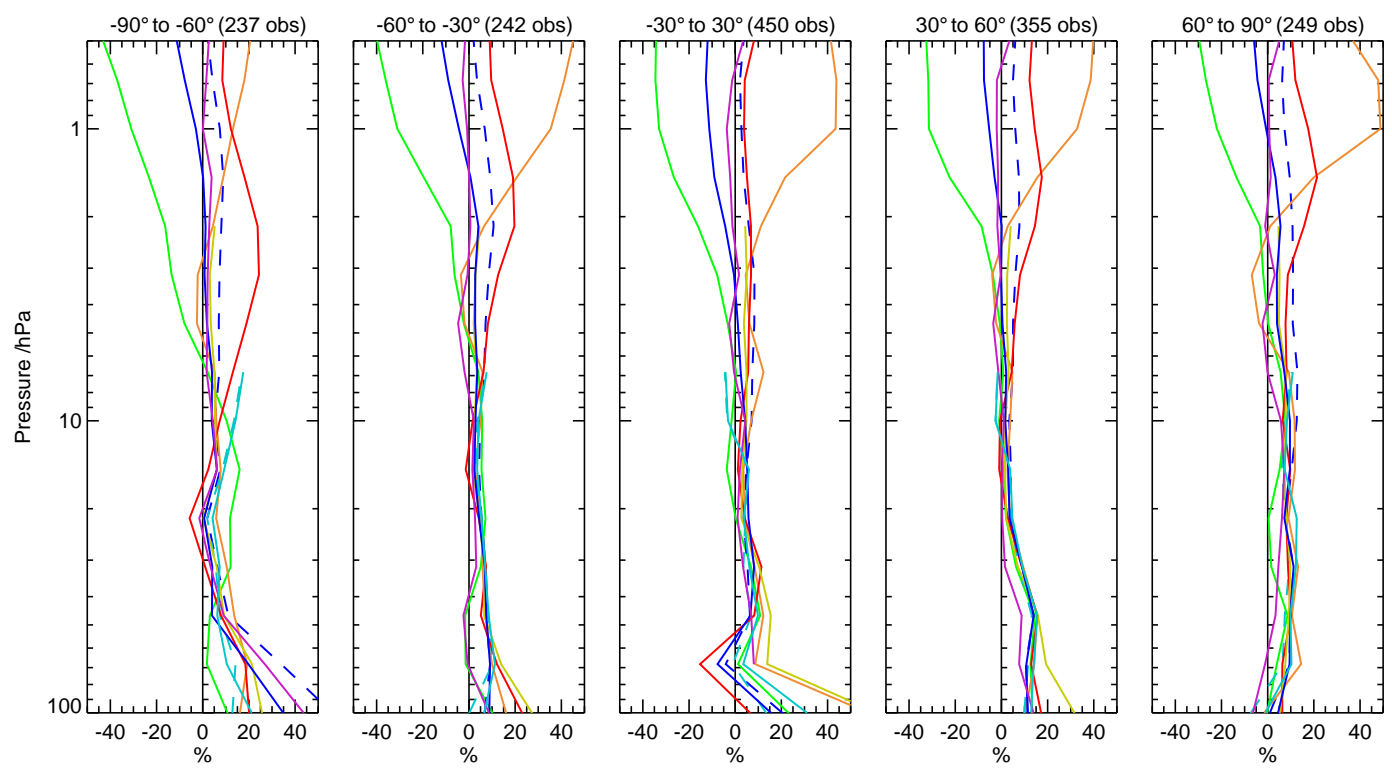

Fig. 11. Mean of (analysis - HALOE) ozone, normalised by climatology, in latitude bands for the period 18 August 2003 to 30 November 2003. Statistics are shown for the ECMWF MIPAS, DARC, KNMI TEMIS, BASCOE v3d24 and v3q33, MOCAGE-PALM Cariolle v2.1 and Reprobus, Juckes and MIMOSA analyses. See colour key in Fig. 3.

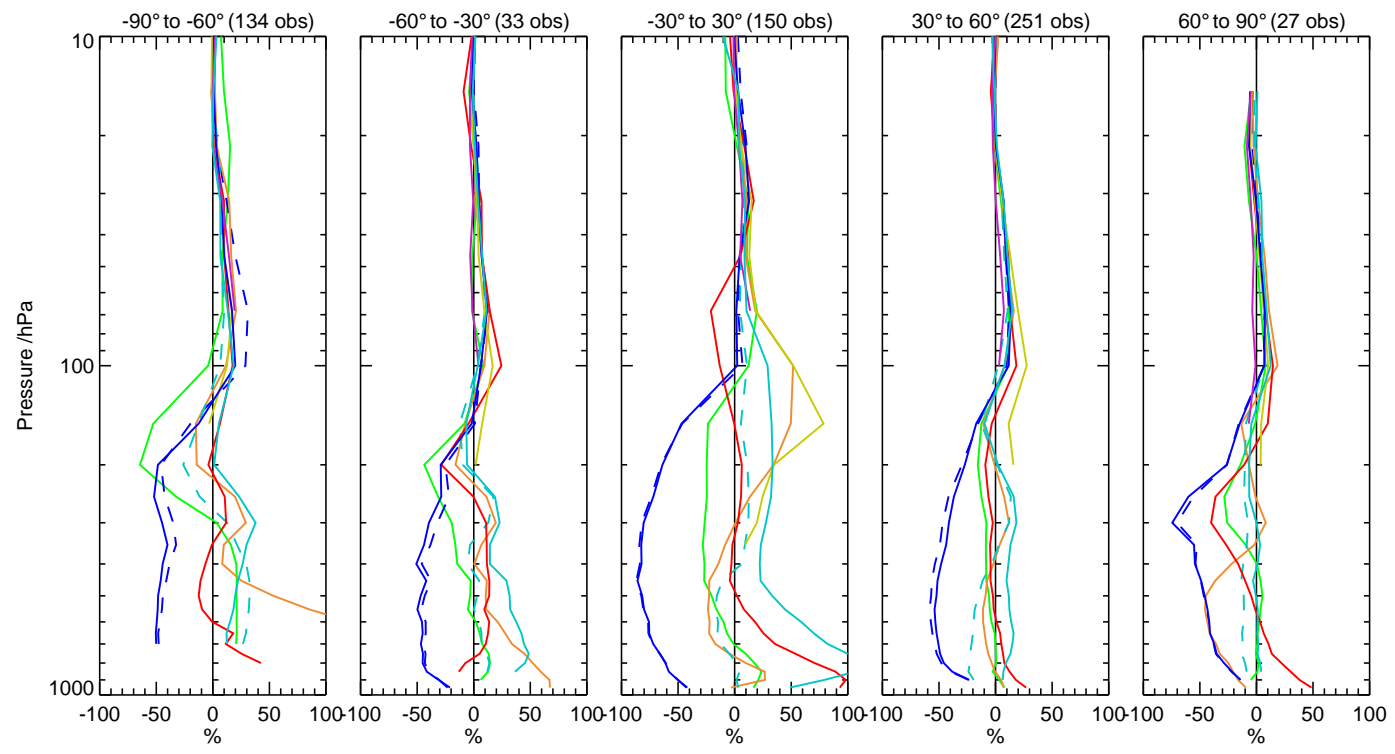

Fig. 12. Mean of (analysis - sonde) ozone, normalised by climatology, in latitude bands for the period 18 August 2003 to 30 November 2003. The analyses shown are the same as in Fig. 11; see colour key in Fig. 3.

tions at these levels (Sect. 5.6). A number of analyses show very large biases in the troposphere, examined in Sect. 5.5.

At $\mathrm{SH}$ high latitudes, KNMI TEMIS analyses stand out with a positive bias of 10 to $15 \%$ between $10 \mathrm{hPa}$ and $30 \mathrm{hPa}$ against MIPAS, HALOE and sonde. Above and below this level, the bias becomes negative. There is a $\sim 60 \%$ negative bias against sonde at $200 \mathrm{hPa}$. The KNMI TEMIS analyses are the only analyses examined here to be based only on total column, rather than profile, observations. Hence the analysed vertical profile is model-determined. These biases are in accord with previous studies which have shown that analyses based on total column observations provide a poorer description of the vertical structure than do those based on profile observations (Struthers et al., 2002; Dethof, 2003a). 

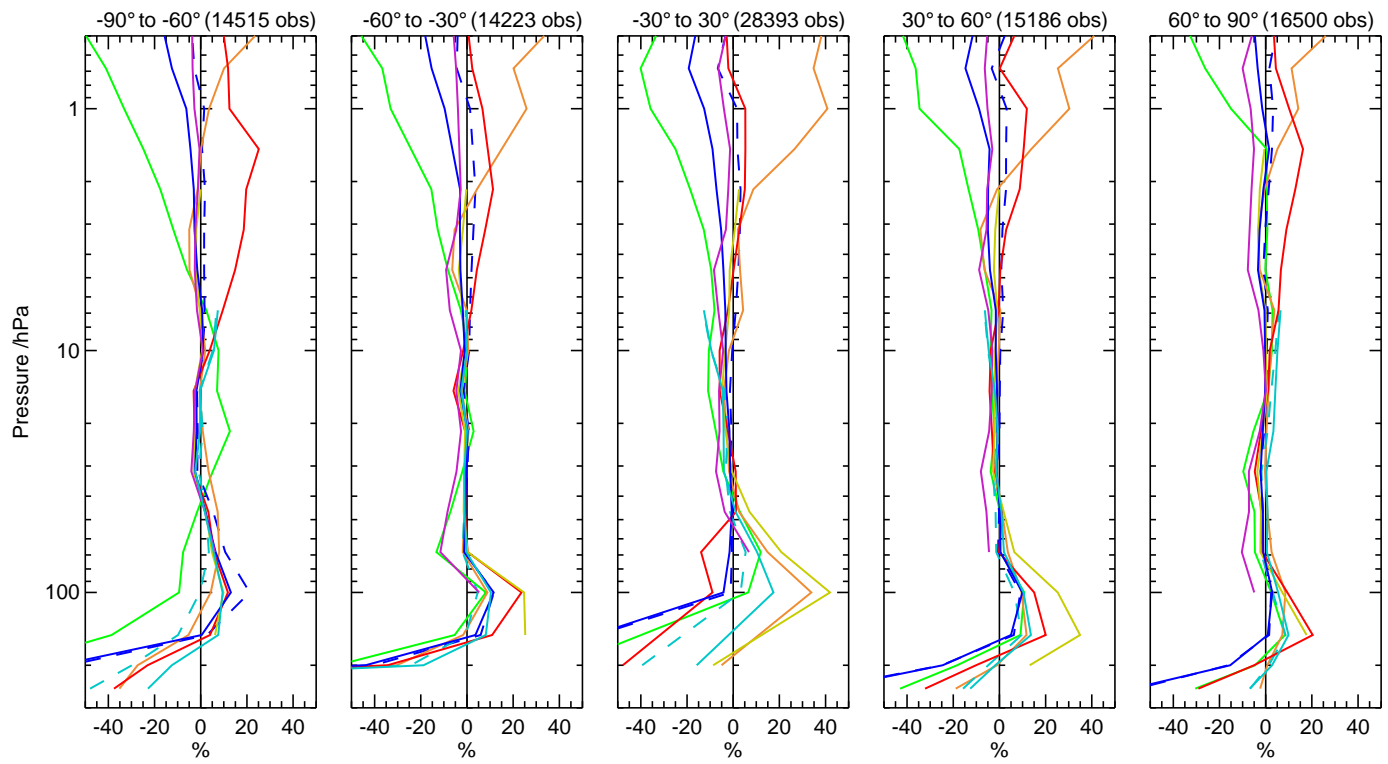

Fig. 13. Mean of (analysis - MIPAS) ozone, normalised by climatology, in latitude bands for the period 18 August 2003 to 30 November 2003. The analyses shown are the same as in Fig. 11; see colour key in Fig. 3.

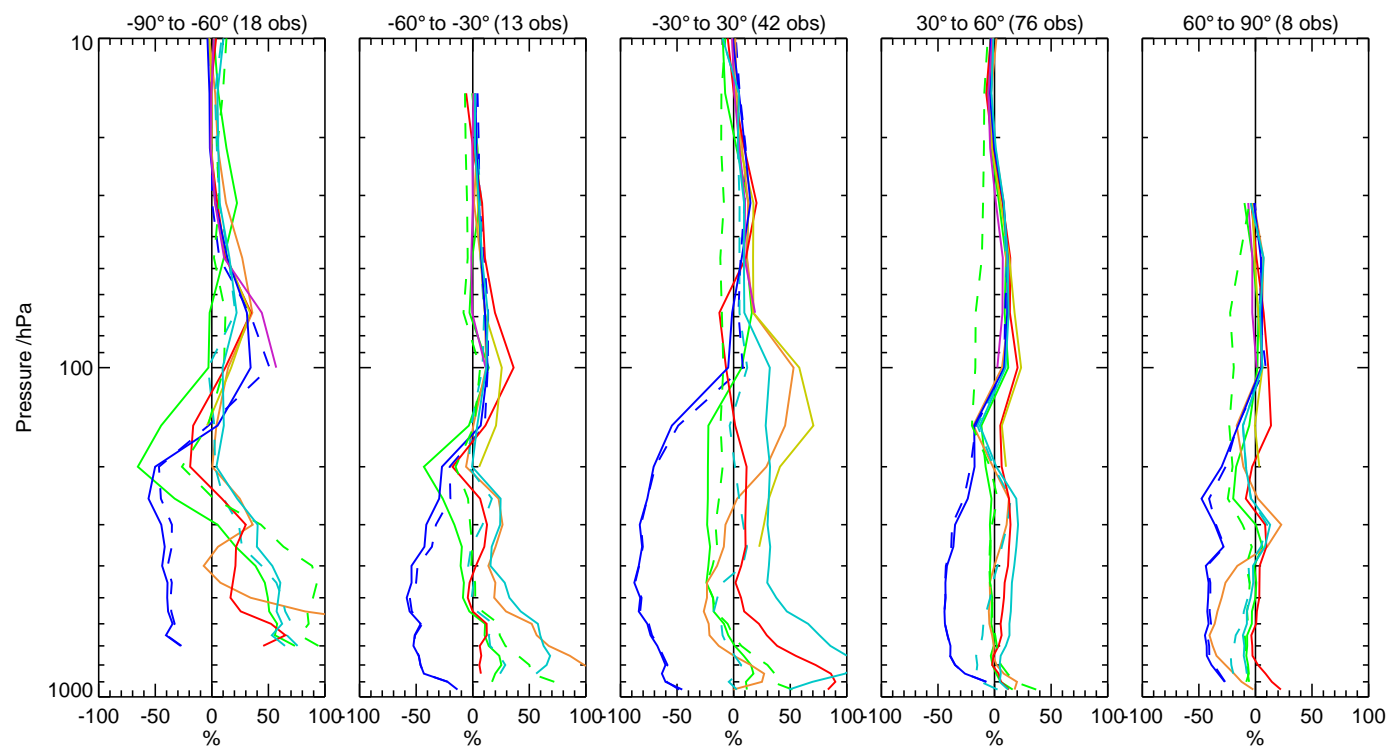

Fig. 14. Mean of (analysis - sonde) ozone, normalised by climatology, in latitude bands for the month of November 2003 . The analyses shown are the same as in Fig. 11, but with the addition of the KNMI SCIAMACHY profile analyses; see colour key in Fig. 3.

The Juckes analyses are essentially unbiased when compared to MIPAS observations assimilated on isentropic levels (Juckes, 2006a), yet biases exist when compared to MIPAS on pressure levels in Fig. 13 in this comparison. There are two likely explanations. First, the Juckes analyses have lower vertical resolution than other analyses (see Table 1). There will be errors associated with interpolation onto the higher vertical resolution of the common grid. Second, the interpo- lation will be affected by biases (e.g., Dethof, 2004) between the MIPAS temperatures used to assimilate the data on isentropic levels, and the ECMWF temperatures used here in the vertical transformation to pressure levels. This bias results in a small vertical uncertainty in the pressure assignment of both the Juckes and MIMOSA ozone profiles. Making the comparison in observation space would have helped eliminate these problems. 

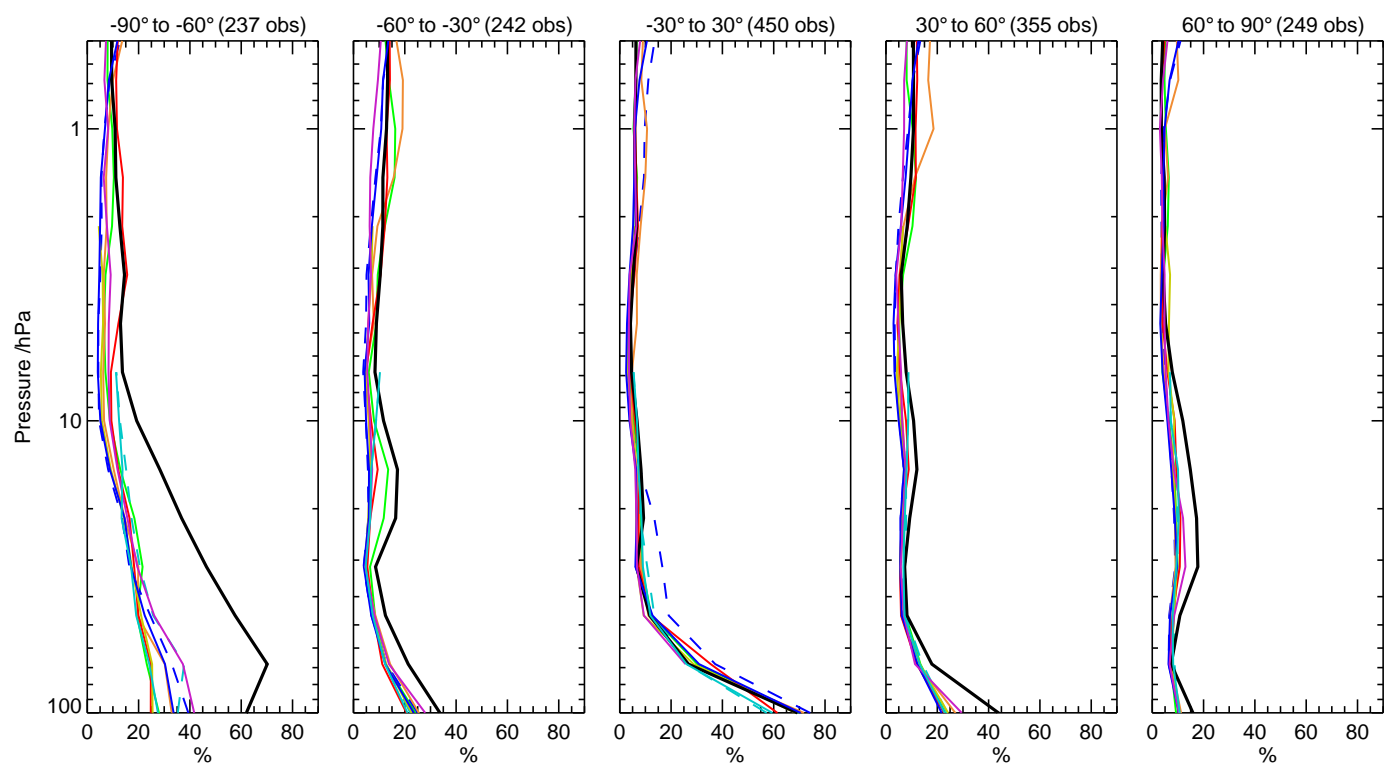

Fig. 15. Standard deviation of (analysis - HALOE) ozone, normalised by climatology, in latitude bands for the period 18 August 2003 to 30 November 2003. The analyses shown are the same as in Fig. 11, but with the addition of the Logan/Fortuin/Kelder climatology (black line); see colour key in Fig. 3.
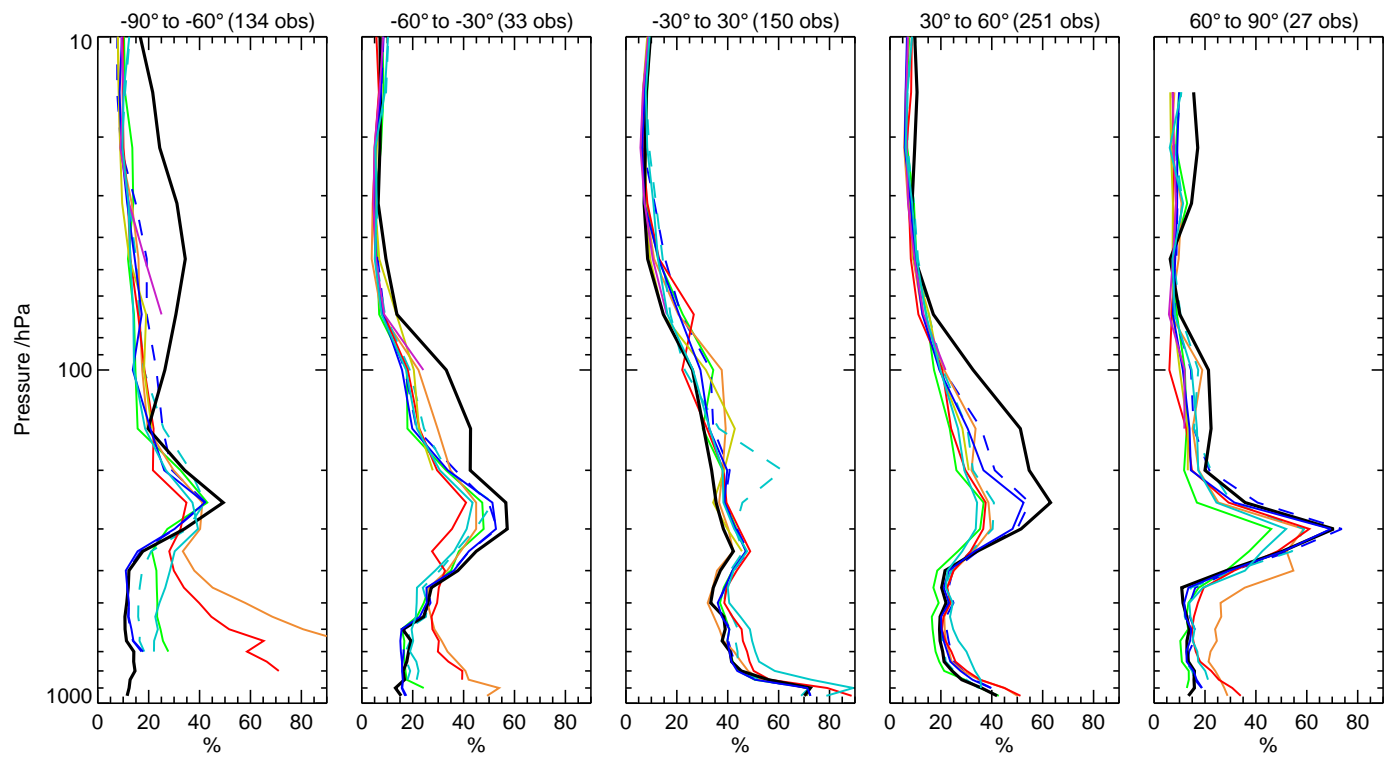

Fig. 16. Standard deviation of (analysis - sonde) ozone, normalised by climatology, in latitude bands for the period 18 August 2003 to 30 November 2003. The analyses shown are the same as in Fig. 11, but with the addition of the Logan/Fortuin/Kelder climatology (black line); see colour key in Fig. 3.

Next we examine biases in the KNMI SCIAMACHY profile analyses. SCIAMACHY profiles were only available in quantity for assimilation for October and November during the intercomparison period; it would not make sense to include them in the August to November figures. Instead, Fig. 14 shows the analysis biases against sonde in Novem- ber; October biases are similar and are not shown. In the lower stratosphere $(200 \mathrm{hPa}$ to $10 \mathrm{hPa})$, the SCIAMACHY profile analyses have up to $20 \%$ negative bias compared to sonde and (figures not shown) HALOE and MIPAS. Especially in the NH the SCIAMACHY profile analyses are notably different from the others. This bias is thought to be due 

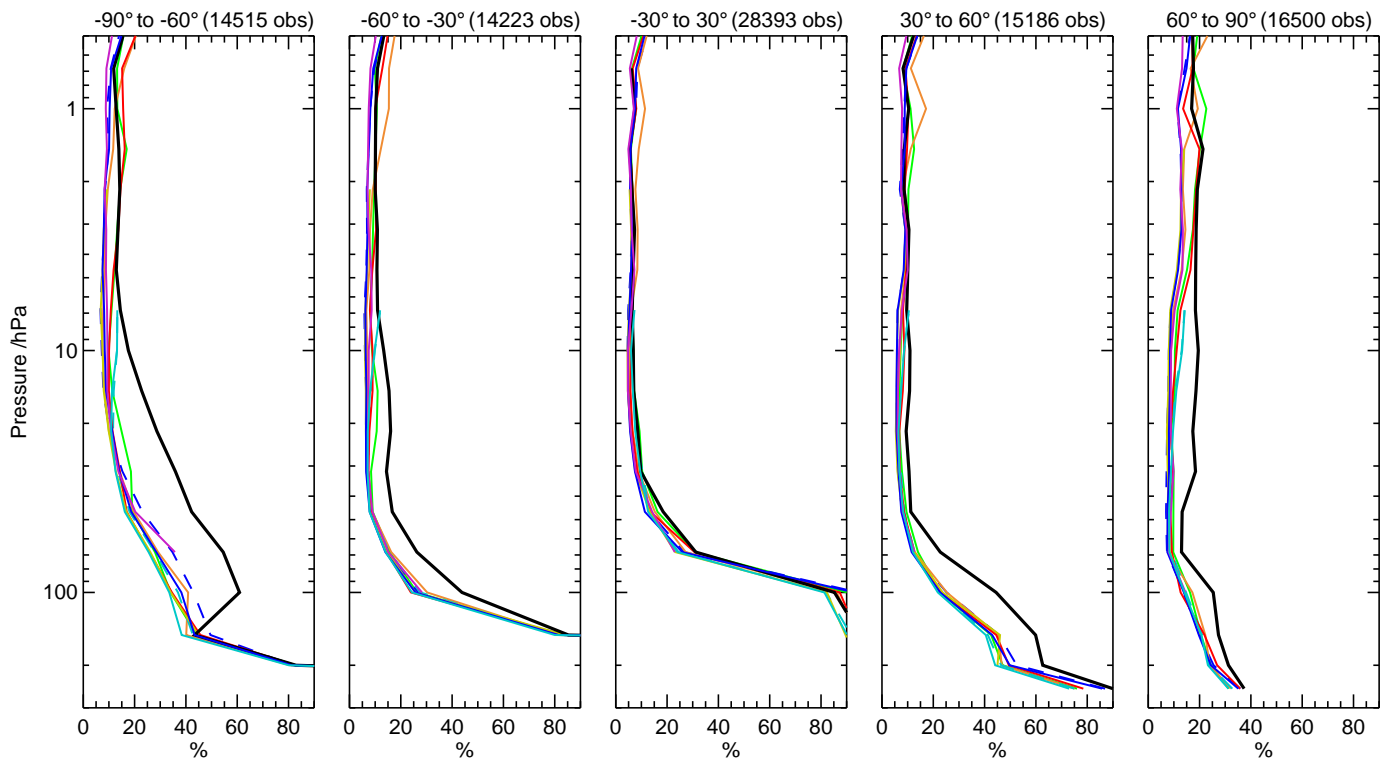

Fig. 17. Standard deviation of (analysis - MIPAS) ozone, normalised by climatology, in latitude bands for the period 18 August 2003 to 30 November 2003. The analyses shown are the same as in Fig. 11, but with the addition of the Logan/Fortuin/Kelder climatology (black line); see colour key in Fig. 3.

to problems with the shape of the SCIAMACHY profiles in the lower stratosphere. Against HALOE and MIPAS (figures not shown) biases are no more than $+20 \%$ in the upper stratosphere and mesosphere, which is comparable in magnitude to many of the other analyses (Figs. 11 and 13).

\subsection{Standard deviations}

Figures 15,16 and 17 show the standard deviations of differences between analyses and HALOE, sonde and MIPAS ozone respectively, normalised against climatology (see Sect. 4). As a reference point, these figures also show the standard deviations of the differences between observations and the Logan/Fortuin/Kelder climatology. Again, statistics are only plotted at a particular level if the number of colocations is at least $50 \%$ (25\% in the case of MIPAS) of the total number of profiles available.

Analyses demonstrate smaller standard deviations than climatology throughout the high latitude stratosphere, and in the midlatitude lower stratosphere and upper troposphere $(10 \mathrm{hPa}$ to $300 \mathrm{hPa})$. Looking at the monthly statistics (not shown), at high latitudes the analyses demonstrate the largest improvements over climatology in September, October and November. During these months, the analyses are succesfully capturing the strong synoptic variability due to the onset of the top-down breakup of the polar vortex in the $\mathrm{SH}$ (e.g., Lahoz et al., 2006) and the increasing surf-zone activity around the developing vortex in the NH. The midlatitude UTLS is also a region of high variability in ozone. Ozone has strong gradients across the tropopause; in data assimila- tion systems these gradients are expected to provide dynamical information, particularly on the horizontal position of the polar front (e.g., Riishøjgaard, 1996; Peuch et al., 2000; Hudson et al., 2003). However, the analyses show relatively large standard deviations here, though they are still an improvement over climatology.

In other regions, particularly the tropical stratosphere, analyses do little better, or even worse, than climatology. These are regions of relatively low synoptic variability, reflecting long-term balances between transport, radiation and chemistry. In the upper stratosphere, ozone is close to photochemical equilibrium. If analyses do worse than climatology, this suggests they have unrealistic spatial variability in ozone fields that are in nature relatively smooth. Such variability can come from noisy observational increments and poorly modelled transport (examined in Sect. 5.6 for the tropical tropopause), and in the upper stratosphere from problems with linearised ozone chemistry schemes (Sect. 5.8). Nevertheless, with standard deviations around 5\% through the mid and upper stratosphere in the tropics, the analyses are clearly still quite accurate here.

In the mid and upper stratosphere (above $50 \mathrm{hPa}$ ), standard deviations are typically less than $10 \%$ against HALOE and (to $10 \mathrm{hPa}$ only) sonde data. However, the DARC, ECMWF and KNMI TEMIS analyses show exceptions to this in some regions of the upper stratosphere, as well as in the mesosphere. Section 5.8 shows that the main explanation for this is problems with the use of linearised ozone photochemistry schemes. 

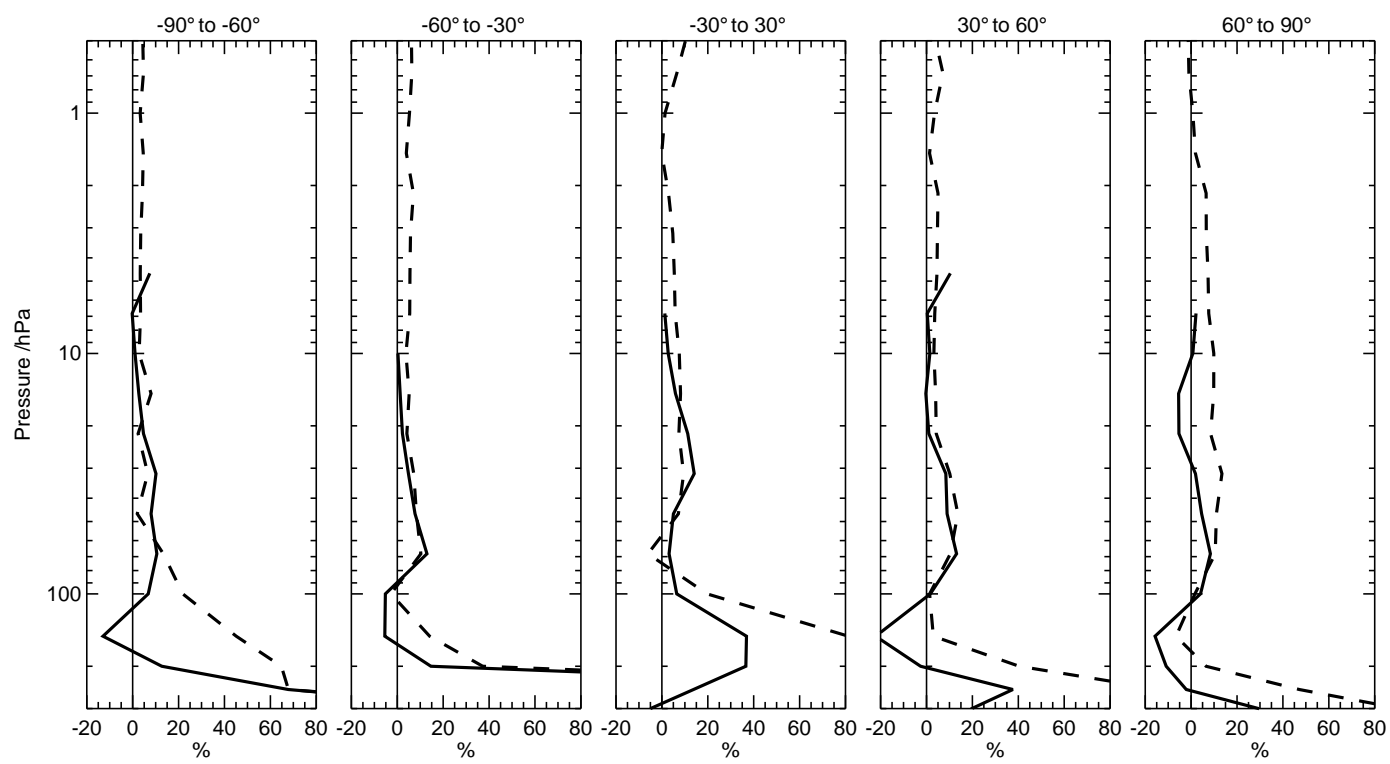

Fig. 18. Estimates of the mean of (MIPAS - sonde) (solid) and (MIPAS - HALOE) (dotted), using BASCOE v3q33 analyses as a transfer standard, and normalising by climatology, in latitude bands for the period 18 August 2003 to 30 November 2003.

In the lower stratosphere (between $50 \mathrm{hPa}$ and $100 \mathrm{hPa}$ ), standard deviations against sonde, HALOE and MIPAS become larger than in the upper stratosphere. In the midlatitude comparisons $\left(30^{\circ} \mathrm{S}\right.$ to $60^{\circ} \mathrm{S}$ and $30^{\circ} \mathrm{N}$ to $60^{\circ} \mathrm{N}$ ) analyses show standard deviations against MIPAS, HALOE and sonde of $\sim 20 \%$ at $100 \mathrm{hPa}$. At high latitudes and in the tropics, standard deviations are larger, and there are notable differences between the analyses themselves. Sections 5.6 and 5.7 explain these differences in terms of the analyses' ability to capture respectively the ozone hole and the tropical tropopause. The larger standard deviations of the troposphere are examined in Sect. 5.5.

At $100 \mathrm{hPa}$ in the tropics, there is also disagreement between the data types. The standard deviations of (analysis - sonde) are $\sim 30 \%$, compared to $\sim 85 \%$ for (analysis - MIPAS) and $\sim 70 \%$ for (analysis - HALOE). There appears to be a large degradation in the quality of the satellite observations at these levels. Section 5.3 investigates further.

\subsection{MIPAS validation}

Previous sections have indicated differences in ozone amounts between MIPAS, ozonesonde and HALOE. The bias between MIPAS and independent data can be estimated from the statistics shown in Figs. 11, 12 and 13 as, for example, $($ MIPAS - sonde $)=($ MIPAS - analysis $)-($ sonde analysis). The analyses are used as a transfer standard. This has the advantage, compared to colocating pairs of observations, that all available observations are included in the sample. Also, it is possible not just to calculate biases, but to compare standard deviations. The analyses will have their own biases, varying in space and time, but these will cancel out if each set of observations is sampling equally in space and time.

Figure 18 summarises the biases calculated using BASCOE v3q33 analyses as the transfer standard. These are chosen for their small standard deviations against independent data through the stratosphere (Figs. 15 and 16), though Fig. 18 would in general be similar no matter which analyses are chosen (figures not shown). The sampling patterns of sonde and HALOE vary with time (Figs. 5 and 7) and the biases show some variation when broken down by month, but the features identified in Fig. 18 are broadly typical of the period. In the upper stratosphere (above $\sim 30 \mathrm{hPa}$ ), MIPAS measures approximately $5 \%$ more ozone than HALOE. In the lower stratosphere (100 to $30 \mathrm{hPa}$ ), MIPAS has a high bias of typically $10 \%$ compared to sonde and HALOE. This lower stratospheric bias is a consistent feature of other studies that have considered the calibration of MIPAS for a variety of periods and data versions (Dethof, 2003a,b, 2004; Fischer and Oelhaf, 2004; Wargan et al., 2005; Geer et al., 2006b). No bias was seen by Migliorini et al. (2004), who took account of the MIPAS averaging kernels, but considered only a very small number of retrievals, or by Juckes (2006a) who made comparisons on isentropic levels rather than pressure levels.

At $100 \mathrm{hPa}$ in the tropics and midlatitudes, MIPAS appears unbiased against HALOE and sonde, though results should be treated with caution due to the problems of vertical interpolation around the sharp gradients of the tropopause (see Sect. 4.1). At $200 \mathrm{hPa}$, the high bias against HALOE is likely a problem with HALOE observations, given the known 
degradation in quality at $100 \mathrm{hPa}$ and below (Bhatt et al., 1999). Biases between MIPAS and sonde are larger below $100 \mathrm{hPa}$.

Finally, we examine the fact that standard deviations between MIPAS and analyses are in some cases much larger than between sonde and analyses. Section 5.2 noted that, at the tropical tropopause, MIPAS standard deviations are $\sim 85 \%$, compared to $\sim 30 \%$ for sonde. HALOE standard deviations were similarly large, associated with the aforementioned degradation in quality of HALOE retrievals at these levels. For the comparison between MIPAS and sonde standard deviations, it must be noted that their sampling patterns are different (Figs. 4 and 5). Did this affect the statistics? We made a separate comparison (no figure shown) considering just the region between $10^{\circ} \mathrm{S}$ and the equator, where there is good sampling from the SHADOZ sondes. The results were very similar to those noted above: at $100 \mathrm{hPa}$, against sonde, standard deviations were relatively small $(15 \%$ to $35 \%)$; against MIPAS, relatively large ( 95\%). Hence MIPAS, like HALOE, is much less reliable near the tropical tropopause. The degradation in the quality of the satellite retrievals at these levels is likely due to the effects of undetected cloud (e.g., Dethof, 2003b), as well as the sharp vertical gradients in temperature and ozone, particularly so at the tropical tropopause. These sharp gradients are hard to resolve using an instrument with a $\sim 3 \mathrm{~km}$ vertical resolution.

\subsection{TOMS}

Total column ozone observations are sensitive to ozone predominantly in the lower stratosphere, with a smaller contribution from the troposphere. In mean terms, BASCOE and KNMI TEMIS analyses are closest to TOMS total columns (Fig. 19a). The other analyses show typically 20 to $40 \mathrm{DU}$ positive biases against TOMS, consistent with the typically positive biases seen against sonde and HALOE in the lower stratosphere, particularly (by examination of the monthly statistics) in September, October and November in the ozone hole region. The BASCOE analyses also have a positive bias in the lower stratosphere, but a negative bias in the troposphere (Fig. 12) contributes to closer agreement with TOMS. The good agreement between KNMI TEMIS analyses and TOMS probably reflects good agreement between TOMS and the assimilated total columns from SCIAMACHY. However, this does not say anything about the KNMI TEMIS ozone profiles: in fact a small negative bias against ozonesonde at around $200 \mathrm{hPa}$ helps balance positive biases in the lower stratosphere (Fig. 12).

In terms of standard deviation (Fig. 19b), there is little to separate the analyses, with magnitudes typically $10 \mathrm{DU}$ to $20 \mathrm{DU}$. The ECMWF operational analyses have clearly larger standard deviations in the southern hemisphere, but they were assimilating only SBUV and very limited GOME observations during August and September. KNMI TEMIS analyses have the lowest standard deviations, as (a)

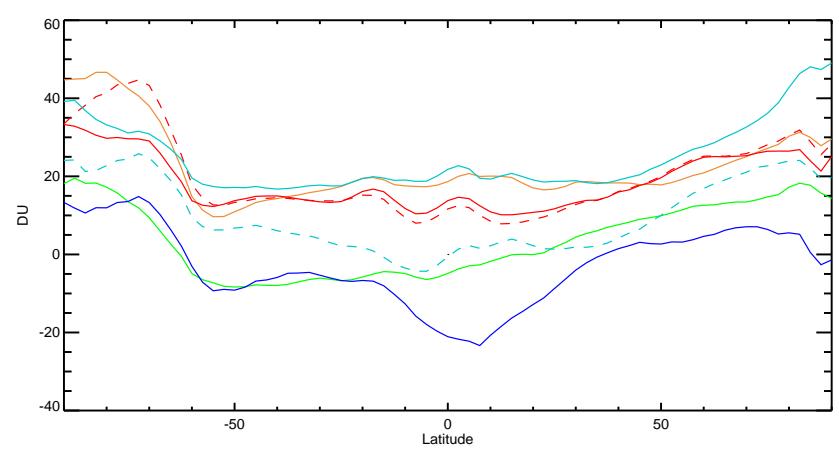

(b)

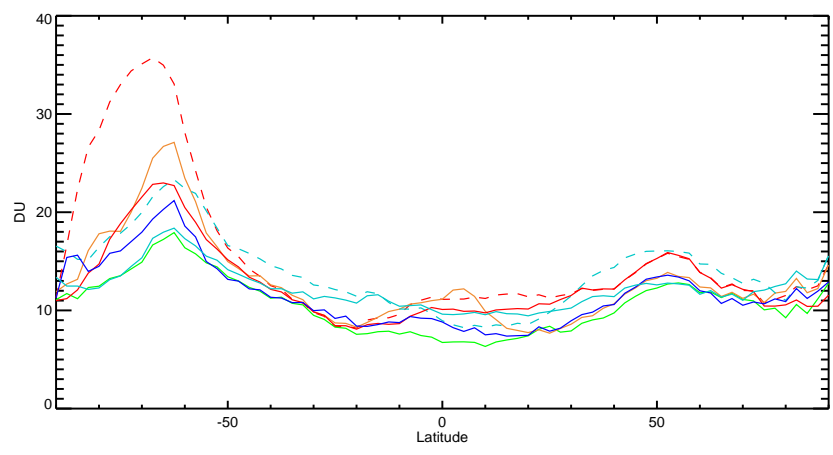

(c)

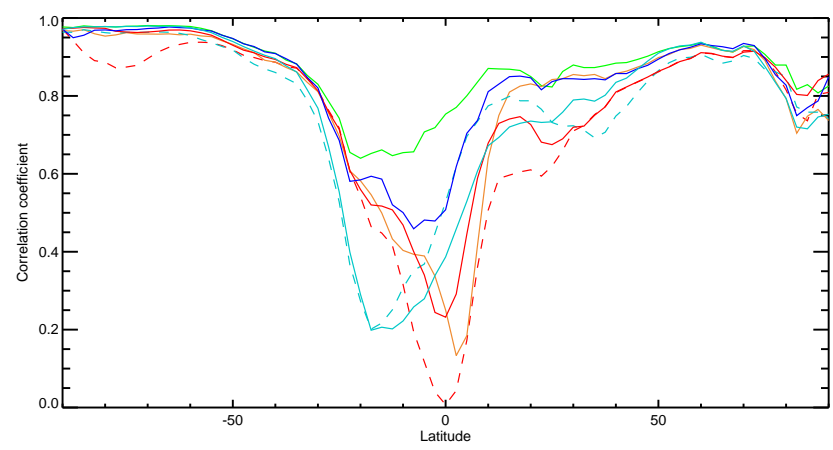

Fig. 19. (a) Mean and (b) standard deviation of (analysis - TOMS) total column ozone; (c) correlation coefficient of analysed against TOMS ozone, in $5^{\circ}$ latitude bins for the period 18 August 2003 to 30 November 2003. Shown are the ECMWF operational and MIPAS, MOCAGE-PALM Cariolle v2.1 and Reprobus, KNMI TEMIS, DARC and BASCOE v3q33 analyses. See colour key in Fig. 3.

again would be expected due to the assimilation of SCIAMACHY columns. The correlation coefficient (e.g., Spiegel and Stephens, 1999) between analysis and TOMS, calculated from samples in $5^{\circ}$ latitude bands, reveals wider differences between analyses in the tropics (Fig. 19c).

The time evolution of the standard deviation (Fig. 20) reveals a $\sim 10$ day spinup at the beginning of July in the 


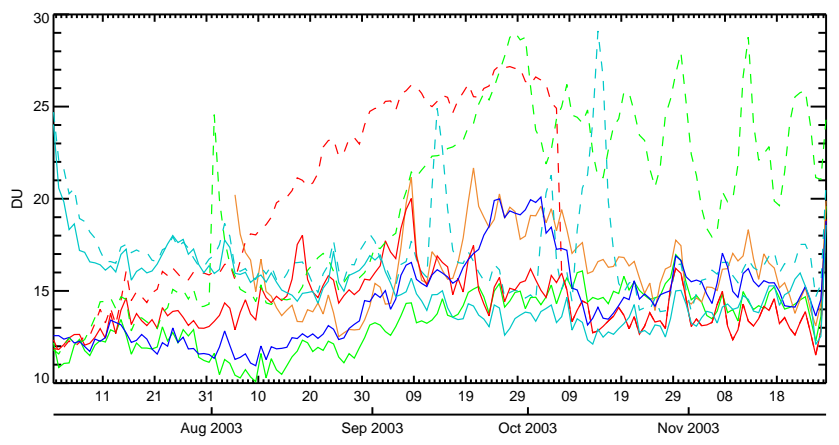

Fig. 20. Standard deviation of (analysis - TOMS) total column ozone, globally averaged, shown daily from 18 August 2003 to 30 November 2003. Analyses shown are as Fig. 19 but with the addition of the KNMI SCIAMACHY profile analyses; see colour key in Fig. 3.

MOCAGE-PALM runs, and a similar spinup in the DARC analyses. These were started on 4 August; standard deviations against TOMS decline until about 14 August. This length of spinup is expected in the DARC system and is longest in the lower stratosphere (Geer et al., 2006b). The other analyses are sections of longer runs that were started well before July; hence no spinup is seen. The ECMWF operational analyses show particularly large standard deviations through August and September, when GOME observations were very limited. Smaller standard deviations are seen when MIPAS are assimilated (throughout the ECMWF MIPAS run, and after 7 October in the ECMWF operational analyses). This shows that the assimilation of MIPAS data substantially improved the ECMWF analyses. See Dethof (2003a) for more details.

Figure 20 also includes statistics for the KNMI SCIAMACHY profile analyses. These are largely based on the free running model before October. In September, large standard deviations of $\sim 25 \mathrm{DU}$ are comparable to those from the ECMWF operational analyses, also based on limited observations. However, in October and November, assimilation of SCIAMACHY profiles does not reduce the standard deviations to the $\sim 15 \mathrm{DU}$ level of the other analyses. This is in contrast to the ECMWF analyses, which improve markedly when MIPAS observations are assimilated. This supports the conclusion that SCIAMACHY profile observations are not as good quality as MIPAS in the lower stratosphere.

\subsection{Troposphere}

Little observational information on ozone has been incorporated in the analyses in the troposphere. However, the ECMWF and KNMI TEMIS analyses include total column ozone observations and MIPAS provides some information down to $400 \mathrm{hPa}$. None of the models represents detailed tropospheric chemistry or ozone sources, though

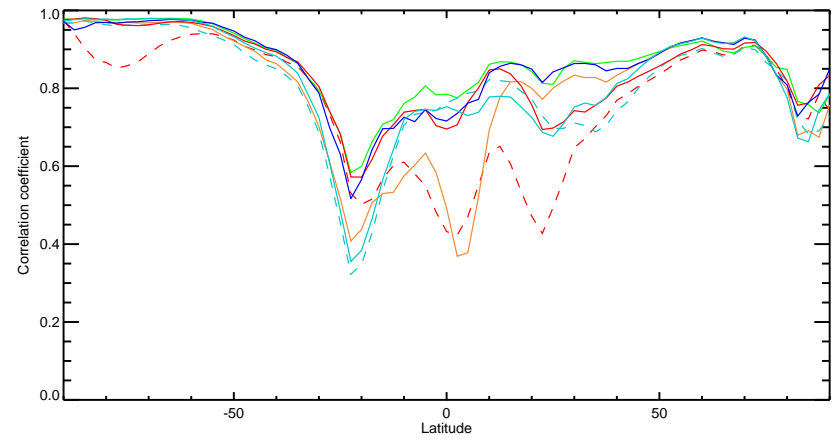

Fig. 21. Correlation coefficient of analysed against TOMS total column ozone, in $5^{\circ}$ latitude bins for the period 18 August 2003 to 30 November 2003. Logan (1999) climatology ozone fields have been substituted into the analyses at $200 \mathrm{hPa}$ and below. Analyses shown are as Fig. 19; see colour key in Fig. 3.

the MOCAGE-PALM Reprobus run does include uppertropospheric chemistry. However, it would be hoped that if the stratospheric ozone distribution were reasonably well analysed, the models should be able to approximate fluxes of ozone into the upper troposphere. Unlike other analyses, DARC and ECMWF include vertical correlations in their specification of ozone background errors; if these correlations were to link tropospheric ozone to that at higher levels (thus spreading observational information downwards) this would likely be erroneous and thus cause problems in the troposphere. In general, we should expect analysed tropospheric ozone to be of very poor quality, as is indeed revealed by the large biases and standard deviations against sonde in Figs. 12 and 16.

In the troposphere, standard deviations of (analysis sonde) range between typically $10 \%$ and $80 \%$ (Fig. 16). Above $400 \mathrm{hPa}$ and outside the tropics, the analyses demonstrate improvements over climatology. Figure 6 gives an example. Most analyses are able to capture a small bulge in ozone between $200 \mathrm{hPa}$ and $300 \mathrm{hPa}$, but do not capture the full strength of what is likely a laminar intrusion of stratospheric air. In these situations, the analyses are limited by their vertical and horizontal resolution. Additionally, the use of vertical background error correlations in the DARC and ECMWF systems is likely to have further smoothed the vertical structure. Below $400 \mathrm{hPa}$, none of the analyses does better than climatology: it would be better to use climatological ozone.

A similar conclusion can be drawn from the TOMS data. Standard deviations and correlations with TOMS can be improved by substituting the Logan (1999) climatology into the analyses at $200 \mathrm{hPa}$ and below. Figure 21 shows that for the ECMWF, MOCAGE-PALM, BASCOE and DARC analyses, correlations become substantially larger between $20^{\circ} \mathrm{S}$ and $10^{\circ} \mathrm{N}$ compared to Fig. $19 \mathrm{c}$, where the analyses have been used throughout the atmosphere. A small degra- 
dation in ECMWF operational analyses at $20^{\circ} \mathrm{N}$ is likely associated with the poor quality of ozone fields before 7 October (Sect. 5.4). Examination of the column fields (not shown) reveals that the analyses typically lack structure in the equatorial total column ozone field. When the Logan climatology is substituted in the troposphere, the combination of tropospheric climatology and stratospheric analyses appears to give a better representation of the zonal tropical "wave-1" pattern in total column ozone (Thompson et al., 2003b), which is due to zonal variations in tropospheric ozone. It could be argued that since the Logan (1999) analyses are partly based on TOMS tropospheric residuals, improved agreement with TOMS fields might be expected. It is also possible that the tropical variability of TOMS columns may be affected by high clouds. Nevertheless, Thompson et al. (2003b) have confirmed the tropospheric zonal "wave1 " using independent ozonesonde data.

Some analyses show particularly large biases when compared to sonde (Fig. 12). The BASCOE analyses, in contrast to their good performance at upper levels, also have a particulaly large negative bias (typically $50 \%$, all latitudes), along with high standard deviations. We do not have an explanation for the BASCOE problems. A number of other large biases are associated with problems in the linear ozone chemistry schemes. DARC analyses have a large positive bias in the SH near the ground, associated with the Cariolle v1.0 scheme; the same problems are likely responsible for high standard deviations against sonde in the SH in DARC and ECMWF analyses (Fig. 16). MOCAGE-PALM Cariolle v2.1 analyses have a positive bias, particularly in the tropics, and this is known to be a problem with v2.1 of the Cariolle scheme. See Geer et al. (2006a) for more information on these biases in the linear ozone chemistry schemes. One strategy to eliminate these very large tropospheric biases is to impose a relaxation to an ozone climatology: the KNMI TEMIS analyses use this technique and are relatively succesful in minimising bias against ozonesonde.

\subsection{Tropical tropopause}

At the tropical tropopause, there is a wide variation between analyses. In general, standard deviations against ozonesonde are relatively high $(30 \%$ at $100 \mathrm{hPa})$ and few analyses do much better than zonal mean climatology (Fig. 16). There are positive biases compared to sonde at $100 \mathrm{hPa}$ between $30^{\circ} \mathrm{S}$ and $30^{\circ} \mathrm{N}$ in the MOCAGE-PALM Cariolle v2.1, MIMOSA and DARC analyses (Fig. 12). In contrast, ECMWF ozone amounts are $10 \%$ lower than sonde at $100 \mathrm{hPa}$. KNMI TEMIS, BASCOE and MOCAGE-PALM Reprobus are approximately consistent with sonde.

The principal factors that will influence ozone analyses at the tropical tropopause are the assimilated observations, the model's ability to transport ozone correctly, and the ozone background error covariance matrix. The vertical ozone gradient is very large in the UTLS, so variability in the ozone

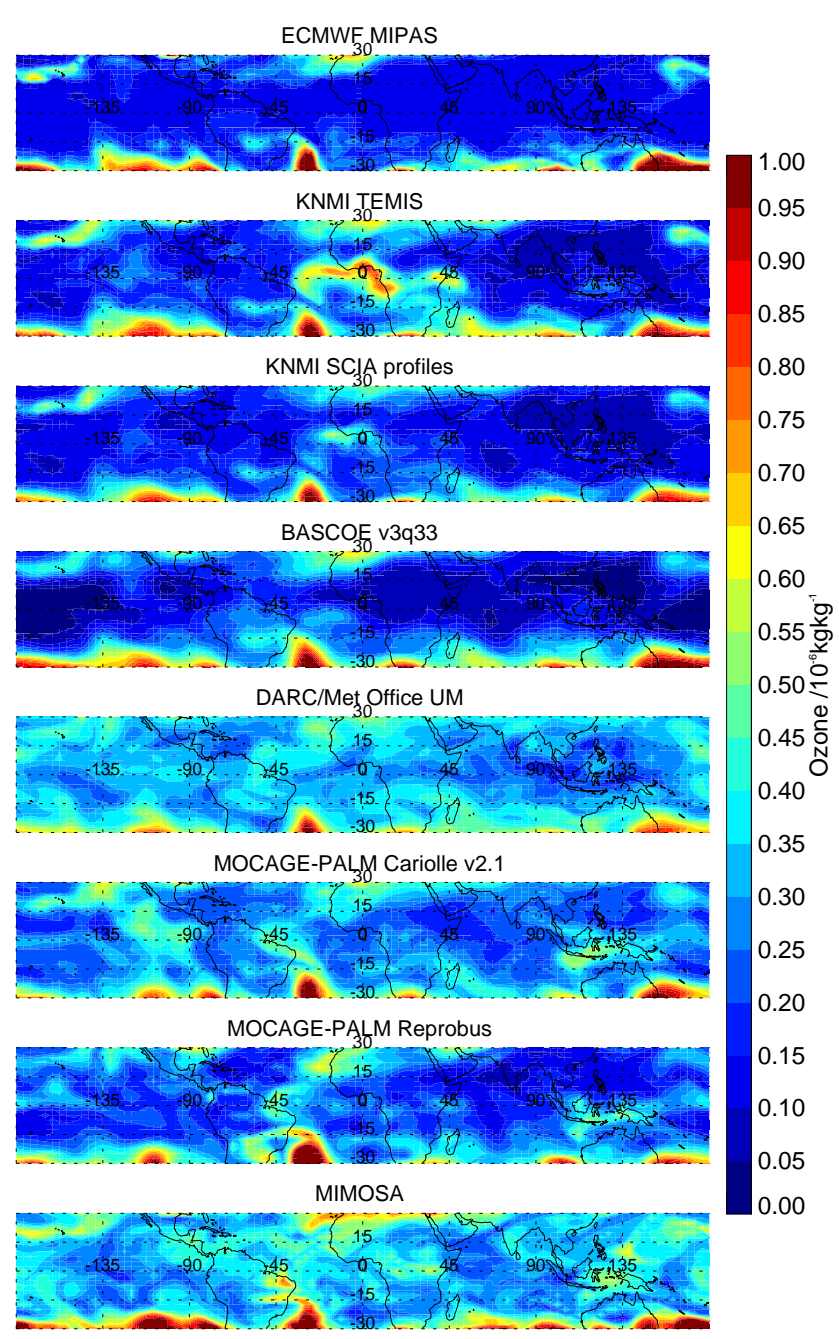

Fig. 22. Ozone analyses at $100 \mathrm{hPa}$ on 17 October 2003 , in ppmm, shown on a Mercator projection with a latitude range $30^{\circ} \mathrm{S}$ to $30^{\circ} \mathrm{N}$ about the equator.

field can come through vertical advection, which could be due either to large-scale motion or convective activity. Ozone photochemical relaxation times are $\sim 100$ days in this region (e.g., Cariolle and Déqué, 1986), so chemistry should be unimportant, but contradicting this, differences are seen here between the two MOCAGE-PALM analyses.

Figure 22 shows examples of the analysis fields at $100 \mathrm{hPa}$ on 17 October 2003. Through most of the tropics, ozone amounts appear generally uniform and very low. The positive biases of the MOCAGE-PALM Cariolle v2.1, MIMOSA and DARC analyses are obvious by comparison to the other analyses. At the edge of the tropics, there is a transition to the higher ozone values of the surf-zone (see e.g., Plumb, 2002).

Between $10^{\circ} \mathrm{S}$ and the equator, the ECMWF MIPAS analyses and zonal mean climatology have the closest agreement to ozonesonde, with standard deviations of $15 \%$ (figure not shown). From Fig. 22 it appears that this good agreement 
with sonde is associated with a very uniform ozone field around the equator at $100 \mathrm{hPa}$. Where other analyses show larger standard deviations of difference against ozonesonde, it is because they have much more ozone variability in the tropics. Based on the comparison with sondes, this variability is unlikely to be real. The zonal invariance of the equatorial UTLS ozone field is examined in more detail by Thompson et al. (2003a, see their Fig. 12).

There are a number of plausible explanations for the problems in the analyses; it is likely that the explanations may be different in different systems. MIPAS ozone is of poorer quality at $100 \mathrm{hPa}$ in the tropics, showing excessive noise (Figs. 16 and 17). It is also well-known that tropical wind fields in assimilated datasets are poorly represented (e.g., Žagar, 2004). When used to transport stratospheric tracers, they produce excessive horizontal mixing between the tropics and the extratropics, and excessive vertical mixing between the UTLS and higher levels in the stratosphere (e.g., Schoeberl et al., 2003; Tan et al., 2004).

In the case of the ECMWF analyses, Fig. 2 suggests that MIPAS data have very little impact on the ozone distribution at $100 \mathrm{hPa}$ in the tropics. Hence, the smooth field is indicative of good quality transport. In CTM studies, the ECMWF 4D-Var operational analyses have been seen to produce better age-of-air values, i.e. better stratospheric transport and mixing, than earlier 3-D-Var analyses such as ERA-40 (e.g., Scheele et al., 2005). However, ozone amounts are 10 to $20 \%$ lower than sonde at $100 \mathrm{hPa}$ and $68 \mathrm{hPa}$ (see Fig. 12); this may be due to continuing excessively fast transport from the troposphere.

The KNMI (TEMIS and SCIAMACHY profile), MIMOSA and BASCOE analyses are driven by ECMWF operational winds, so it might be expected that they also would produce smooth ozone fields. Instead they still show excessive structure in the tropics. A possible explanation (e.g., Stohl et al., 2004) may be the use of 6-hourly (3-hourly in the case of KNMI SCIAMACHY profile analyses) snapshots of the winds in the CTMs, as compared to the winds within the ECMWF model which evolve every timestep. The smoother ozone field in the KNMI SCIAMACHY profile analyses compared to those based on SCIAMACHY total columns may be due to the difference in observations, but is also consistent with the known improvements in KNMI's TM5 model when using 3-hourly winds (as in the SCIAMACHY profile analyses) rather than 6-hourly winds (as in the SCIAMACHY TEMIS analyses), which would have improved transport in the UTLS (Bregman et al., 2006).

The MOCAGE-PALM Reprobus analyses are smoother than the MOCAGE-PALM Cariolle v2.1 analyses. The inclusion of upper-tropospheric chemistry in the Reprobus runs does appear to improve the field. In these analyses, ozone chemistry appears to be faster than that in the Cariolle v2.1 scheme, which has a photochemical relaxation time of $\sim 100$ days at these levels.
Problems in the DARC analyses are thought to be due to poor transport. DARC analysis runs that assimilate SBUV instead of MIPAS (not shown here) produce similar structure in the ozone field at the tropopause; hence MIPAS is unlikely to be the cause of the variability in the DARC analyses.

In summary, only the ECMWF analyses are able to simulate a smooth ozone distribution at the tropical tropopause. Other analyses show spurious variability in the ozone field for a variety of reasons linked to modelled ozone transport, as well as the relatively poorer quality of the observations themselves.

\subsection{Ozone hole}

At high latitudes in the southern hemisphere, at levels between $100 \mathrm{hPa}$ and $50 \mathrm{hPa}$, there are variations in the performance of the analyses, which in general overestimate the ozone amount, and have standard deviations of up to $20 \%$ against ozonesonde. These discrepancies come mostly during the later part of the intercomparison period, between September and November, and can be explained by the analyses' ability to capture the development of the ozone hole. Apart from KNMI, who assimilated SCIAMACHY, and ECMWF who assimilated MIPAS v4.59 alongside GOME and SBUV, all other analyses assimilated only MIPAS v4.61, so any differences between them must be due to differences either in the models or in the use of the observations.

Figure 23 shows the time evolution of analysed ozone over the South Pole compared to sonde observations at $32 \mathrm{hPa}$, $46 \mathrm{hPa}$ and $68 \mathrm{hPa}$. Figure 1 shows the situation at $68 \mathrm{hPa}$ on 31 August 2005, with ozone depletion already under way in a ring around the South Pole, in regions where sunlight has returned after the winter. At the South Pole itself, ozone depletion began at around 5 September, progressing to almost complete ozone destruction by early October (e.g. Fig. 23b). In November 2003, the vortex was periodically displaced off the pole by growing anticyclones, but the lower stratosphere vortex $(\sim 100 \mathrm{hPa}$ to $\sim 50 \mathrm{hPa})$ itself remained relatively intact until December (Lahoz et al., 2006). In general, the analyses capture the rapid, early ozone depletion quite well, but few are able to achieve complete ozone destruction in October. The oscillations in ozone amount associated with periodic vortex displacements in November are captured well at $32 \mathrm{hPa}$ and $46 \mathrm{hPa}$. However, most analyses also show oscillations and a rapid rise in ozone amount at $68 \mathrm{hPa}$, where this is not seen the sonde observations.

MOCAGE-PALM Cariolle v2.1 analyses, and ECMWF (using v1.2 of the Cariolle scheme), achieve a near-complete ozone destruction in October using a simple parametrization of heterogeneous ozone depletion. Both v1.2 and v2.1 of the Cariolle scheme have a term which is activated in sunlight below 195K (e.g., Dethof and Hólm, 2004). In the MOCAGE-PALM Cariolle v2.1 analyses, it was found that this term should not be switched on before the sun reaches a zenith angle of $87^{\circ}$. An earlier version of the MOCAGE- 
PALM Cariolle v2.1 analyses (not shown) instead used a zenith angle of $94^{\circ}$ which gave erroneous early ozone depletion in September at $32 \mathrm{hPa}, 20 \mathrm{hPa}$ and $10 \mathrm{hPa}$. This early ozone depletion was also thought to be influenced by a possible low bias in ARPEGE temperatures, and the fact that MIPAS data are not assimilated beyond $80^{\circ} \mathrm{S}$, meaning the ozone field is less constrained by observations there.

MOCAGE-PALM Reprobus and BASCOE v3d24 analyses each use detailed descriptions of heterogeneous chemistry. The Reprobus analyses achieve a good description of the full ozone destruction. In contrast, in the BASCOE v3d24 analyses, 1 to 2 ppmm of ozone remain through October at $46 \mathrm{hPa}$ and $68 \mathrm{hPa}$. This problem has been traced back to an unrealistically low initial background aerosol distribution. Specifically, low aerosol number densities led to overestimated PSC growth and sedimentation. The unrealistically quick depletion of PSCs from the vortex led to a severe underestimation of the heterogeneous reaction rates from mid-winter onwards. Using the same model as BASCOE, Daerden et al. (2006) illustrate that a more realistic initial background aerosol distribution leads to a much better description of the polar winter processes, including the ozone destruction. In the newer version of BASCOE, v3q33, the microphysics scheme was replaced by a parametrization, which is independent of the aerosol distribution and hence does not suffer from the same problem. BASCOE v3q33 achieves a more complete destruction of ozone in October.

DARC and KNMI TEMIS analyses each use a cold tracer formulation for heterogeneous ozone depletion (Eskes et al., 2003). Neither analysis shows ozone depletion to lower than $\sim 0.5 \mathrm{ppmm}$ at $68 \mathrm{hPa}$, and this is reflected in a general overestimation compared to ozonesonde in the SH high latitudes (see Fig. 12). DARC use Cariolle v1.0 photochemistry and this produces excessive ozone in the ozone hole (Geer et al., 2006b). If Cariolle v2.1 photochemistry is used instead, the correct full ozone depletion is produced (Geer et al., 2006a). KNMI TEMIS analyses use the LINOZ photochemistry scheme, which does not produce excessive ozone in the ozone hole, and so it is not clear why ozone amounts are not depleted further.

The Juckes and MIMOSA isentropic analyses include no modelled ozone chemistry. In the Juckes analyses, 1 ppmm to $2 \mathrm{ppmm}$ of ozone remain through October at $46 \mathrm{hPa}$ and $68 \mathrm{hPa}$. The $\sim 10 \%$ positive bias in MIPAS at these levels, as compared to ozonesonde (Sect. 5.3), may be a partial explanation for the problem. The MIMOSA analyses show several spikes of high ozone through October at $68 \mathrm{hPa}$, though not at $46 \mathrm{hPa}$ or $100 \mathrm{hPa}$ (not shown). At $68 \mathrm{hPa}$, MIMOSA ozone fields are very noisy within the ozone hole; Fig. 23c reflects the advection of patches of high and low ozone over the South pole in the analyses during October.

The rapid increase of ozone in November at $68 \mathrm{hPa}$ in all analyses except KNMI TEMIS is contrary to sonde observations of continuing low ozone values (Fig. 23c), yet is seen throughout the vortex in the analysis fields (no fig- (a)

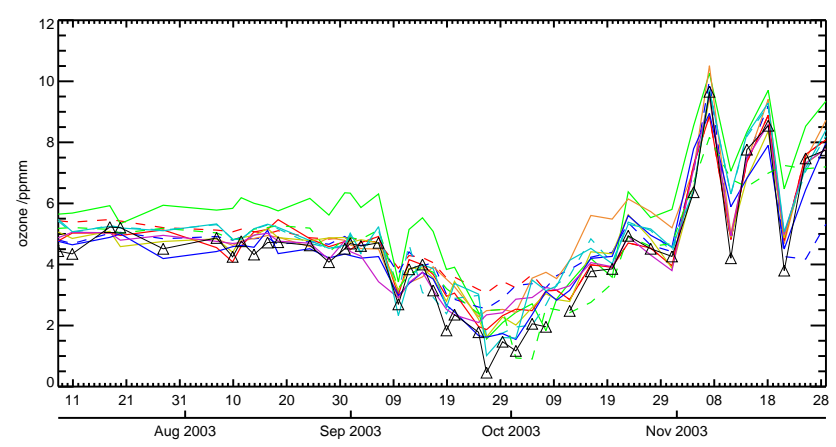

(b)

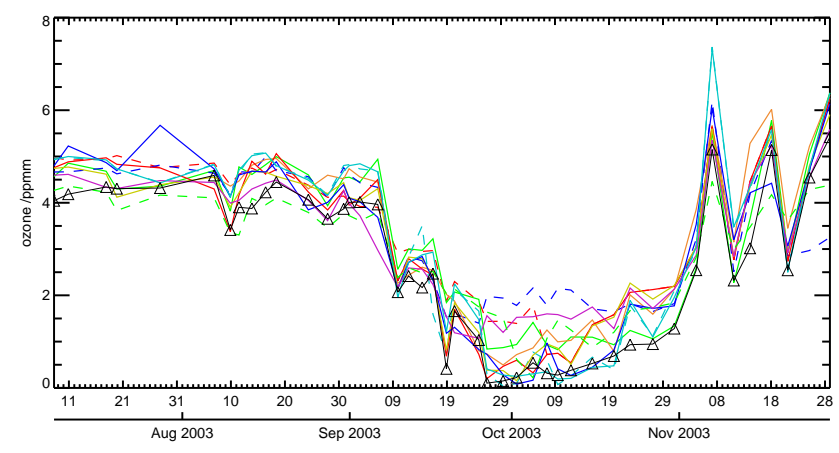

(c)

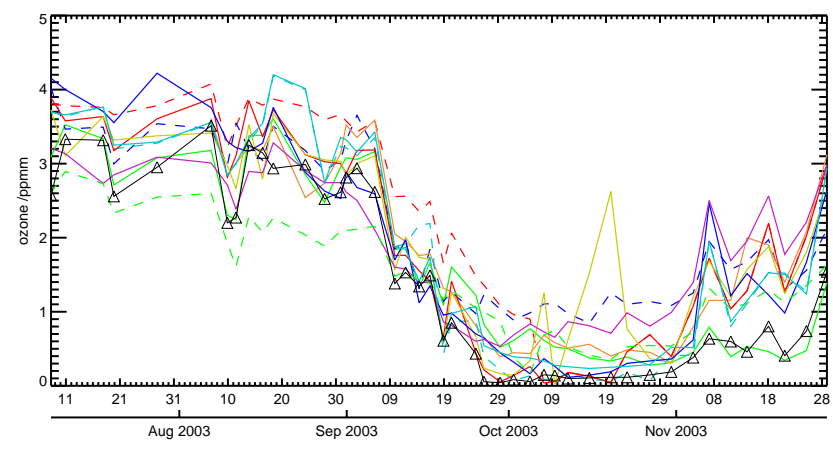

Fig. 23. Ozonesonde measurements (triangles joined by black line) and analyses (see key Fig. 3) at (a) $32 \mathrm{hPa}$, (b) $46 \mathrm{hPa}$ and (c) $68 \mathrm{hPa}$ over the South Pole. Analysis points are only shown on days when the sonde made a measurement. Shown are the ECMWF operational and MIPAS, DARC, KNMI TEMIS and SCIAMACHY profile, BASCOE v3d24 and v3q33, MOCAGE-PALM Cariolle v2.1 and Reprobus, Juckes and MIMOSA analyses.

ures shown). The KNMI TEMIS analyses instead maintain a sharp gradient at the vortex edge and almost complete ozone depletion within, in common with ozonesonde observations. The others show an ozone hole that both shrinks and fills in at these levels, in common with the MIPAS observations (figure not shown). An explanation would be the $\sim 3 \mathrm{~km}$ vertical resolution of MIPAS. It is likely that either the vertical 

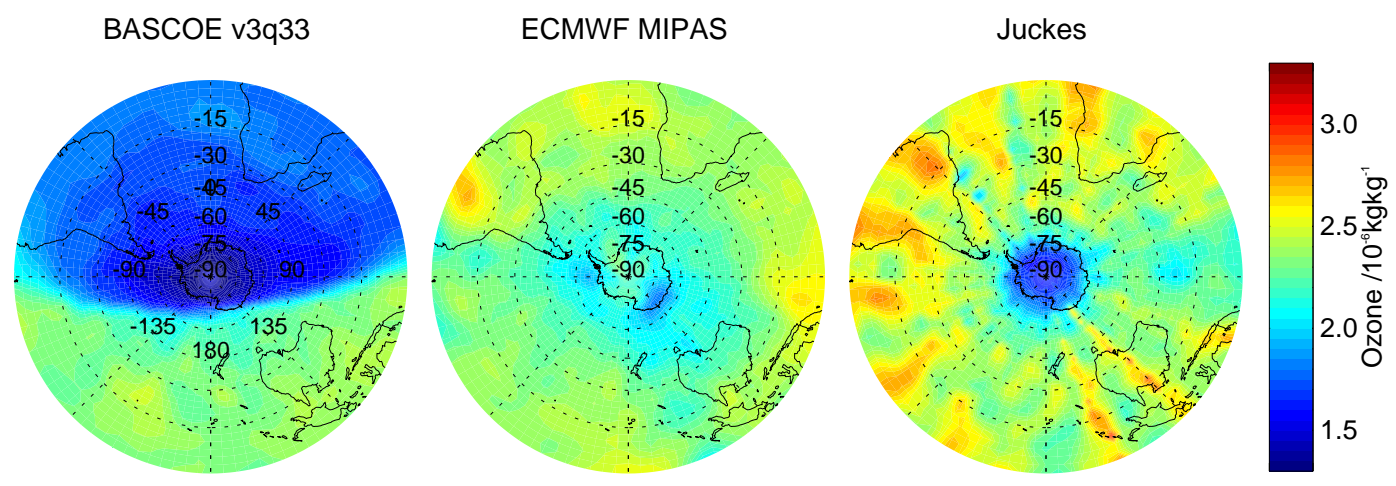

Fig. 24. Ozone analyses in the mesosphere at $0.32 \mathrm{hPa}$ on 15 November 2003. Projection is polar stereographic, bounded by the equator and centred on the South Pole.

resolution, or vertical interpolation of MIPAS, is smearing information from higher levels down to the $68 \mathrm{hPa}$ level. At $46 \mathrm{hPa}$, a similar rapid increase in ozone is confirmed in both analyses, ozonesonde (Fig. 23b), and MIPAS (not shown), as the vortex breaks down at these levels.

\subsection{Upper stratosphere and mesosphere}

In the upper stratosphere and mesosphere, where discrepancies exist between analyses, and between analyses and independent data, they can be explained in terms of the modelled ozone photochemistry. In these regions, ozone is close to photochemical equilibrium. Experience with both the KNMI and DARC data assimilation systems shows that the ozone fields are strongly controlled by the linear ozone photochemistry parametrizations (e.g. Eskes et al., 2003; Geer et al., 2006a). At these levels observational increments are largely irrelevant to the analyses. This is clearly seen in Fig. 13: both ECMWF and DARC analyses show large biases against the MIPAS data that they are assimilating. Similarly, errors in modelled ozone transport are largely irrelevant at these levels. However, it is still possible for errors in modelled temperatures to affect the ozone field via the ozone photochemistry (e.g. Geer et al., 2006a).

Above $\sim 0.5 \mathrm{hPa}$, there is a diurnal cycle in ozone that is only represented in the BASCOE analyses, which include detailed chemistry. Comparing to HALOE ozone with a maximum time mismatch of 15 min (Fig. 9) shows that the BASCOE analyses produce a good representation of ozone at these levels. Figure 24 shows examples of analysed ozone fields in the mesosphere. DARC and KNMI analyses are not shown in this figure because of their large biases at these levels (Fig. 11). Linear photochemistry schemes, as used in ECMWF analyses, are daily averaged and do not have a diurnal cycle. Hence, ECMWF produces a relatively uniform ozone field. The Juckes analyses, which do not include modelled ozone chemistry, show stripes caused by the diurnal sampling of the MIPAS ascending and descending orbits. However, at levels below $0.5 \mathrm{hPa}$ where the diurnal cycle is not important, the Juckes analyses are typically as close to HALOE as the BASCOE analyses (standard deviations $<10 \%$, Fig. 15).

Large biases and standard deviations in the KNMI TEMIS and DARC analyses above $5 \mathrm{hPa}$ can be explained by the linear ozone photochemistry schemes employed. The DARC analyses have a positive bias which rises to $40 \%$ at $0.5 \mathrm{hPa}$ (Figs. 11 and 13). The bias is uniform at all latitudes and, by examination of the monthly statistics (not shown), uniform in time. KNMI TEMIS analyses have a uniform negative bias, growing to $-40 \%$ at $0.5 \mathrm{hPa}$. In the DARC analyses presented here, though not in those of Geer et al. (2006b), it was found that the radiation term of the Cariolle scheme (Cariolle and Déqué, 1986) was incorrectly implemented, leading to a discrepancy between analysed overhead column ozone and the scheme's internal climatology, giving a positive forcing in ozone. The month of October was re-run with (a) a correctly implemented Cariolle scheme and (b) the LINOZ scheme (McLinden et al., 2000), as used in the KNMI TEMIS analyses. Figure 25 shows the bias against MIPAS in these October runs. We note that MIPAS is not independent data, but it offers a much better coverage than HALOE for the month of October (Figs. 4 and 7) and that MIPAS and HALOE are biased by no more than $\sim 5 \%$ with respect to each other at these levels (Sect. 5.3). Figure 25 confirms that the DARC biases were due to an incorrect implementation of the Cariolle scheme, which produced excessive ozone in the upper stratosphere and mesosphere. It is also clear that the LINOZ scheme causes an excessive reduction in upper stratospheric and mesospheric ozone, explaining the negative bias in the KNMI TEMIS analyses. McCormack et al. (2004) have already identified these problems with LINOZ. The results of the DARC study of Cariolle schemes are described in more detail in Geer et al. (2006a).

The ECMWF analyses have relatively high standard deviations (15\%) versus HALOE in the SH high latitudes, between $10 \mathrm{hPa}$ and $1 \mathrm{hPa}$, and positive biases of up to $20 \%$ globally 

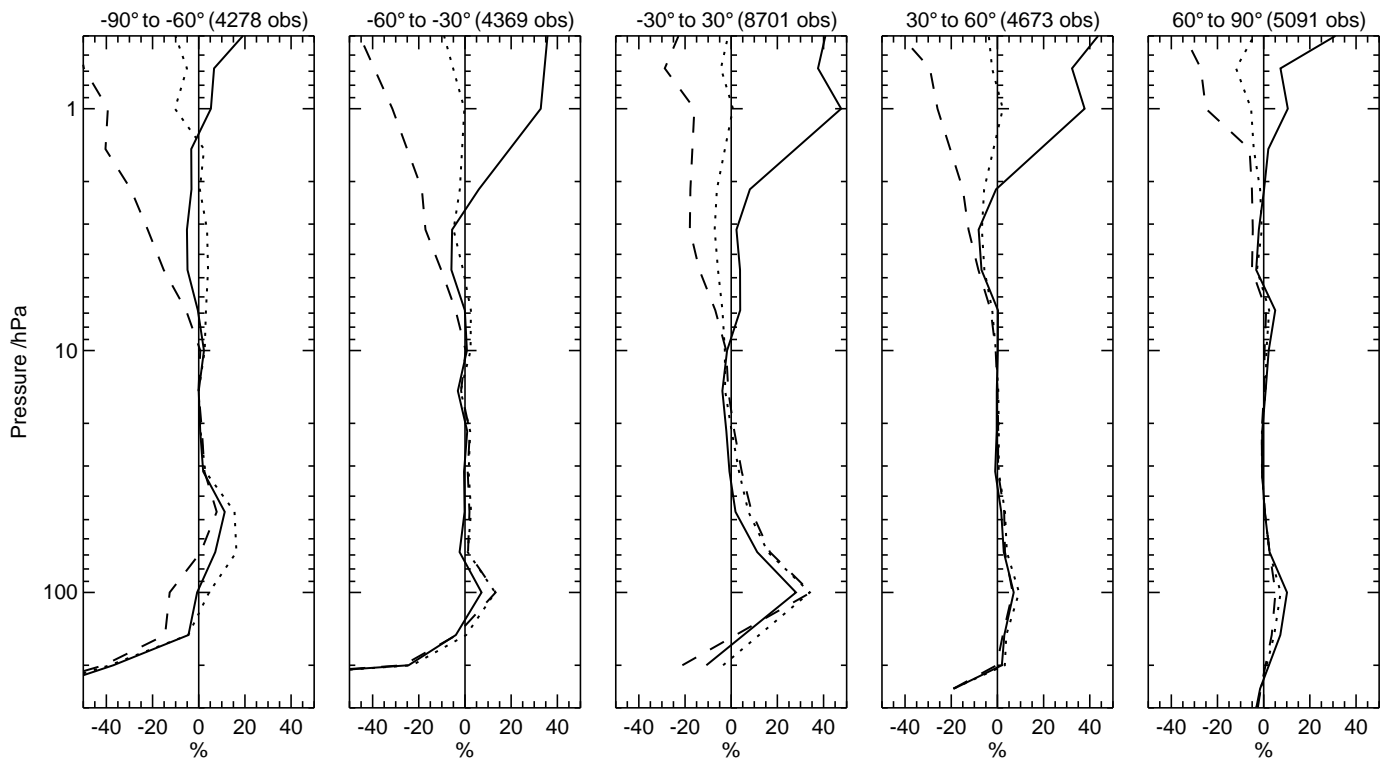

Fig. 25. Mean of (analysis - MIPAS) ozone, normalised by climatology, in latitude bands for the month of October 2003. Figure shows the DARC analyses (solid line), DARC analyses with a correctly implemented Cariolle v1.0 photochemistry scheme (dotted line) and DARC analyses with the LINOZ photochemistry scheme (dashed line).

around these levels (Figs. 11 and 15). Given the DARC and KNMI results, this is also very likely associated with the ozone photochemistry scheme. At high latitudes, there are also known problems in ECMWF upper stratospheric temperatures (Randel et al., 2004). These could have further degraded the output of the ozone photochemistry scheme.

The BASCOE analyses also illustrate the sensitivity of ozone amounts at these levels to the modelled ozone photochemistry. In the v3d24 analyses, the $\mathrm{O}_{2}$ photolysis rate was multiplied by 1.25 to gain better agreement with MIPAS. In the newer v3q33 version of BASCOE, this scaling factor was removed. Figures 11 and 13 show that, compared to MIPAS and HALOE, BASCOE v3q33 analyses have less ozone than v3d24 throughout the upper stratosphere and mesosphere (above $10 \mathrm{hPa}$ ). The difference peaks at $15 \%$ at $0.5 \mathrm{hPa}$; here the v3d24 analyses are closer to MIPAS and the v3q33 analyses are closer to HALOE. This suggests that there are continuing uncertainties in the observations or chemical modelling at these levels.

\section{Conclusion}

This paper introduces the method, initial results and analysis types involved in the ASSET intercomparison. However, many questions remain that will be answered in more detail in further studies by the partners involved.

We have compared 11 different sets of ozone analyses based on 7 different data assimilation systems. Two are NWP systems based on GCMs, and five use CTMs. These sys- tems contain either linearised or detailed ozone chemistry, or in two cases, no chemistry at all. In most analyses, MIPAS ozone data are assimilated. Examples are also shown of SCIAMACHY total column and profile assimilation. The analyses have been interpolated to a common grid and are then compared to ozone profiles from sondes, HALOE, MIPAS, and to total column ozone from TOMS, for the period July to November 2003. Results are presented in percentage terms, relative to a monthly-mean ozone climatology.

To summarise such a wide-ranging intercomparison is a difficult task. The study naturally focuses on problem areas. The troposphere below $400 \mathrm{hPa}$ is poorly represented, as would have been expected, and we see that problems exist in many analyses in the UTLS, in the troposphere, the upper-stratosphere, the mesosphere, and the Antarctic ozone hole region. Nevertheless, at the tropopause and above, at least one analysis system can be found that is capable of producing very good agreement with sonde, HALOE and MIPAS data. From the lower stratosphere to the lower mesosphere $(100 \mathrm{hPa}$ to $0.5 \mathrm{hPa})$ at least one system shows biases less than $\pm 10 \%$. Standard deviations can be less than $10 \%$ above $50 \mathrm{hPa}$ and less than $20 \%$ in the lower stratosphere $(100 \mathrm{hPa}$ to $50 \mathrm{hPa})$. This shows that current assimilation techniques are capable of producing good agreement with independent data. The enhanced skill of the best performing analyses can usually be attributed to better modelling of ozone. The worse performing systems could often be easily improved by following similar modelling techniques. All of these results are contigent upon the good quality of the assimilated ozone dataset: Dethof (2003a) and Wargan et al. 
(2005) have already shown the benefits of MIPAS ozone over operational observations such as SBUV. The intercomparison finds few differences that can be attributed to the assimilation technique (i.e. 3-D-Var, 4-D-Var, Kalman filter or direct inversion, CTM or GCM). It would require focused experiments, rather than intercomparison, to reveal such differences. Overall, the first priority for ozone data assimilation systems is to improve the modelling of ozone chemistry and transport.

We summarise our more detailed results by region:

- Troposphere: No analysis system shows any skill below $400 \mathrm{hPa}$. No system incorporates ozone profile information below $400 \mathrm{hPa}$, and only the MOCAGEPALM Reprobus analyses attempt to model at least upper-tropospheric chemistry realistically. The best performer is the MOCAGE-PALM Reprobus run, with biases less than $\pm 30 \%$ compared to sonde observations in the troposphere. ECMWF, MOCAGE-PALM Cariolle v2.1 and DARC analyses show some areas with larger biases, in general linked to problems with linearised ozone photochemistry schemes (Geer et al., 2006a). Biases can be reduced by instead forcing the ozone photochemistry scheme to relax to ozone climatology, as demonstrated in the KNMI analyses.

- Midlatitude UTLS (50 hPa to $400 \mathrm{hPa}$ ): Here, where it is hoped that dynamical information can be inferred from ozone distributions, standard deviations against ozonesonde are relatively high. For the best performing analyses in this region (ECMWF in the SH and KNMI TEMIS in the NH) these are $20 \%$ to $40 \%$. However, analyses are generally able to produce much better results than ozone climatology.

- Tropical tropopause: Cariolle and Morcrette (2006) have shown that in this region, small changes in the ozone amounts can influence modelled temperatures by several degrees. Ozone distributions should be relatively uniform (Thompson et al., 2003a), but compared to ozonesondes, many analyses show positive biases (up to $50 \%$ ) and excessive structure in the ozone fields, resulting in standard deviations up to $35 \%$ compared to ozonesonde. The reasons vary depending upon the system, but the principal causes are likely to be the known deficiencies in tropical wind fields in data assimilation systems, and a degradation in quality of the MIPAS data at these levels. ECMWF standard deviations are lowest, at $15 \%$, resulting from a smooth ozone field around the equator at $100 \mathrm{hPa}$, suggesting the wind fields and ozone transport in the system are of good quality.

- SH ozone hole: Not all analyses achieve the observed near-complete ozone destruction over the pole during October 2003. The MIMOSA and Juckes analyses show excessively high ozone amounts in the lower stratosphere polar vortex. These systems do not model ozone chemistry and must rely on MIPAS observations, which are noisy and have a small positive bias in these regions. The other analysis systems model heterogeneous ozone depletion in a variety of ways. The simplest approach (included in the Cariolle v1.2 and v2.1 chemistry schemes) is a depletion term which is active in sunlight at temperatures below $195 \mathrm{~K}$. This approach approximates the near-complete ozone depletion in October in the ECMWF analyses and in the MOCAGEPALM system. The KNMI TEMIS and DARC analyses used a cold tracer formulation, and did well, but they did not completely deplete ozone in the ozone hole. In the case of the DARC analyses, complete ozone depletion was prevented by erroneous ozone production in the photochemistry scheme. The sophisticated scheme in the Reprobus model, and the PSC parametrization (Chabrillat et al., 2006 ${ }^{1}$ ) of the BASCOE v3q33 analyses worked very well. In contrast, the BASCOE v3d 24 analyses used the detailed PSCBox microphysics model (Larsen et al., 2000), but with an unrealistically low initial background aerosol field. This resulted in excessively high ozone amounts of $1 \mathrm{ppmm}$ to $2 \mathrm{ppmm}$ in the ozone hole. Daerden et al. (2006) have recently shown that the combination of PSCbox and the BASCOE CTM can succesfully describe polar processes and ozone depletion using a more realistic background aerosol field.

- Upper-stratosphere and lower mesosphere $(5 \mathrm{hPa}$ to $0.5 \mathrm{hPa}$ ): Large biases in DARC, KNMI analyses were linked to problems with modelled ozone photochemistry, which completely dominates over transport or observational increments at these levels. In the DARC analyses the Cariolle scheme was incorrectly implemented; in the KNMI TEMIS analyses known problems of the LINOZ scheme (McCormack et al., 2004) resulted in excessively low ozone. Biases in the ECMWF analyses also likely result from the linear ozone photochemistry scheme. Such problems are relatively easy to resolve (Geer et al., 2006a). In contrast, by choosing not to model chemistry but simply assimilating MIPAS data into an isentropic model, the Juckes analyses, and MIMOSA up to its model top at $\sim 2 \mathrm{hPa}$, have biases and standard deviations against independent HALOE data that are typically as low as the detailed-chemistry BAS$\mathrm{COE}$ analyses. This also illustrates the good quality of MIPAS ozone data. However, there are still uncertainties in the observations or chemistry at these levels. MIPAS ozone is around 5\% higher than HALOE between $30 \mathrm{hPa}$ and $1 \mathrm{hPa}$. This is roughly equivalent to a 25\% change in the $\mathrm{O}_{2}$ photolysis rates in the BAS$\mathrm{COE}$ analyses. In the $\mathrm{v} 3 \mathrm{~d} 24$ analyses, the $\mathrm{O}_{2}$ photolysis rates were scaled by 1.25 to produce good mean agreement with MIPAS at these levels; in v3q33 the scaling 
was removed, leading to better mean agreement with HALOE.

- Mesosphere (above 0.5 hPa): The diurnal cycle in ozone at these levels is not represented except by models using a detailed chemistry scheme. Only the BAS$\mathrm{COE}$ analyses are able to reproduce this. Sassi et al. (2005) show the importance of capturing this diurnal cycle when calculating heating rates in the upper stratosphere and mesosphere.

It has been possible to use the analyses as a transfer standard to compare MIPAS observations to independent data from sonde and HALOE. Statistics are calculated from essentially the full set of available MIPAS profiles. We treat MIPAS as a point retrieval, rather than using averaging kernels. Hence, much caution should be exercised before interpreting these results in terms of the calibration of the instrument, but they do reflect the way MIPAS data is used in the assimilation systems:

- In the mid and upper stratosphere and mesosphere (above $30 \mathrm{hPa}$ ), MIPAS ozone is $\sim 5 \%$ higher than HALOE.

- In the lower stratosphere $(100 \mathrm{hPa}$ to $30 \mathrm{hPa})$ there are typically positive biases compared to sonde and HALOE of $\sim 10 \%$.

- There is excessive noise in observations around the tropical tropopause, likely due to undetected cloud and the sharp vertical transitions in temperature and ozone.

KNMI have assimilated SCIAMACHY total columns (the TOSOMI product) and limb profiles. The total column analyses do almost as well as the MIPAS-based analyses, compared to independent ozone profile data, and they have generally smaller biases and standard deviations compared to independent TOMS total columns than the MIPAS-based analyses. The assimilation of SCIAMACHY profiles is less successful, and causes a negative bias of up to $20 \%$ in the $\mathrm{NH}$ between $200 \mathrm{hPa}$ and $30 \mathrm{hPa}$. It is clear that improvements are needed in the SCIAMACHY limb profile retrievals.

As a first intercomparison between assimilation systems, we believe our strategy was largely succesful. Use of a common grid allowed flexibility in the study of the results. However, improvements could be made by comparing analyses on their original model levels directly to MIPAS in observation space. The minimal standardisation between experiments (other than the assimilation of MIPAS data in most cases) made it easy for teams to participate. This was a tradeoff against the advantages of standardising such features as observational quality control, which would have made it easier to understand differences between systems.

In the intercomparison, systems based on very different approaches show broadly similar agreement with independent data. Nevertheless, the different systems vary widely in the amount of computer time used. The isentropic assimilation schemes (Juckes, 2006a, and MIMOSA) do well against independent observations, and are extremely fast, but do depend on the quality and availability of the MIPAS data. They are not as good in the ozone hole, where there are limitations with the MIPAS observations; the CTMs and GCMs with chemistry do better. The GCM-based analyses require substantially more computer power than the CTM approach, though ozone assimilation is a relatively small additional cost when included in an existing NWP system. It still remains for the proposed benefits of the operational assimilation of ozone in NWP systems (better assimilation of temperature radiances, better heating rates, ozone-radiation feedback, the inference of midlatitude UTLS dynamical information) to be demonstrated with improved forecasts in an operational NWP system.

Acknowledgements. We thank D. Cariolle and F. Daerden for many useful comments and discussions, and the two anonymous referees for helping to improve the paper. For the use of ozonesonde data, we thank both the individual contributors and the projects and databases from which they were obtained: WOUDC, SHADOZ and NDSC. All MIPAS data is copyright ESA, 2003. This work was funded jointly by the authors' institutions and the Assimilation of Envisat Data project (ASSET, http://darc.nerc.ac.uk/asset/), which is a shared-cost project (contract EVK2-CT-2002-00137) co-funded by the Research DG of the European Commission within the RTD activities of the Environment and Sustainable Development sub-programme (5th Framework Programme). The work also benefited from funds from COST action 723 .

Edited by: H. Wernli

\section{References}

Andersson, E. and Järvinen, H.: Variational quality control, Q. J. R Meteorol. Soc., 125, 697-722, 1999.

Austin, J., Shindell, D., Beagley, S. R., Brühl, C., Dameris, M., Manzini, E., Nagashima, T., Newman, P., Pawson, S., Pitari, G., Rozanov, E., Schnadt, C., and Shepherd, T. G.: Uncertainties and assessments of chemistry-climate models of the stratosphere, Atmos. Chem. Phys., 3, 1-27, 2003

Bhartia, P. K., McPeters, R. D., Mateer, C. L., Flynn, L. E., and Wellemeyer, C.: Algorithm for the estimation of vertical ozone profiles from the backscattered ultraviolet technique, J. Geophys. Res., 101, 18 793-18 806, 1996.

Bhatt, P. P., Remsberg, E. E., Gordley, L. L., McInerney, J. M., Brackett, V. G., and Russell, J. M.: An evaluation of the quality of Halogen Occultation Experiment ozone profiles in the lower stratosphere, J. Geophys. Res., 104, 9261-9275, 1999.

Bregman, A., Krol, M. C., Teyssedre, H., Norton, W. A., Iwi, A., Chipperfield, M., Pitari, G., Sundet, J. K., and Lelieveld, J.: Chemistry-transport model comparison with ozone observations in the midlatitude lowermost stratosphere, J. Geophys. Res., 106, 17 479-17 496, 2001.

Bregman, B., Meijer, E., and Scheele, R.: Key aspects of stratospheric tracer modeling, Atmos. Chem. Phys. Discuss., 6, 43754414, 2006 
Cariolle, D. and Déqué, M.: Southern-Hemisphere Medium-Scale Waves and Total Ozone Disturbances in a Spectral General Circulation Model, J. Geophys. Res., 91, 10 825-10 846, 1986.

Cariolle, D. and Morcrette, J.-J.: A linearized approach to the radiative budget of the stratosphere: influence of the ozone distribution, Geophys. Res. Lett., 33, L05806, doi:10.1029/2005GL025597, 2006.

Carslaw, K. S., Luo, B., and Peter, T.: An analytic expression for the composition of aqueous $\mathrm{HNO}_{3}-\mathrm{H}_{2} \mathrm{SO}_{4}$ stratospheric aerosols including gas phase removal of $\mathrm{HNO}_{3}$, Geophys. Res. Lett., 22, 1877-1880, 1995.

Cathala, M.-L., Pailleux, J., and Peuch, V.-H.: Improving global simulations over the upper troposphere-lower stratosphere with sequential assimilation of MOZAIC data, Tellus, 55B, 1-10, 2003.

Chipperfield, M. P., Khattatov, B. V., and Lary, D. J.: Sequential assimilation of stratospheric chemical observations in a three-dimensional model, J. Geophys. Res., 107, 4585, doi:10.1029/2002JD002110, 2002.

Courtier, P., Freydier, C., Geleyn, J.-F., Rabier, F., and Rochas, M.: The ARPEGE project at Météo-France, ECMWF seminar proceedings, Reading, 9-13 Sept. 1991, vol. II, pp. 193-231, 1991.

Davies, T., Cullen, M. J. P., Malcolm, A. J., Mawson, M. H., Staniforth, A., White, A. A., and Wood, N.: A new dynamical core for the Met Office's global and regional modelling of the atmosphere, Q. J. R. Meteorol. Soc., 131, 1759-1782, 2005.

Daerden, F., Larsen, N., Chabrillat, S., Errera, Q., Bonjean, S., Fonteyn, D., Hoppel, K., and Fromm, M.: A 3D-CTM with detailed online PSC-microphysics: analysis of the Antarctic winter 2003 by comparison with satellite observations, Atmos. Chem. Phys. Discuss., 6, 8511-8552, 2006,

http://www.atmos-chem-phys-discuss.net/6/8511/2006/.

Dethof, A.: Assimilation of ozone retrievals from the MIPAS instrument on board ENVISAT, ECMWF Technical Memoranda, 428, http://www.ecmwf.int/publications/, 2003a.

Dethof, A.: Monitoring of retrievals from the MIPAS and SCIAMACHY instruments on board ENVISAT, Contract Report to the European Space Agency, European Centre for Medium-Range Weather Forecasts, available from http://www.ecmwf.int, 2003b.

Dethof, A.: Monitoring and assimilation of MIPAS, SCIAMACHY and GOMOS retrievals at ECMWF, Contract Report to the European Space Agency, European Centre for Medium-Range Weather Forecasts, available from http://www.ecmwf.int, 2004.

Dethof, A. and Hólm, E. V.: Ozone assimilation in the ERA-40 reanalysis project, Q. J. R. Meteorol. Soc., 130, 2851-2872, 2004.

Dufour, A., Amodei, M., Ancellet, G., and Peuch, V.-H.: Observed and modelled 'chemical weather' during ESCOMPTE, Atmos. Res., 74, 161-189, 2004.

El Amraoui, L., Ricaud, P., Urban, J., Theodore, B., Hauchecorne, A., Lautie, N., De La Noe, J., Guirlet, M., Le Flochmoen, E., Murtagh, D., Dupuy, E., Frisk, U., and d'Andon, O. F.: Assimilation of Odin/SMR $\mathrm{O}_{3}$ and $\mathrm{N}_{2} \mathrm{O}$ measurements in a threedimensional chemistry transport model, J. Geophys. Res., 109, D22304, doi:10.1029/2004JD004796, 2004.

Elbern, H. and Schmidt, H.: Ozone episode analysis by fourdimensional variational chemistry data assimilation, J. Geophys. Res., 106, 3569-3590, 2001.

Eskes, H. J., Van Velthoven, P. F. J., Valks, P. J. M., and Kelder, H. M.: Assimilation of GOME total-ozone satellite observations in a three-dimensional tracer-transport model, Q. J. R. Meteorol. Soc., 129, 1663-1681, 2003.

Eskes, H. J., Segers, A. J., and Van Velthoven, P. F. J.: Ozone Forecasts of the Stratospheric Polar Vortex Splitting Event in September 2002, J. Atmos. Sci., 62, 812-821, 2005a.

Eskes, H. J., van der A, R. J., Brinksma E. J., Veefkind, J. P., de Haan, J. F., and Valks, P. J. M.: Retrieval and validation of ozone columns derived from measurements of SCIAMACHY on Envisat, Atmos. Chem. Phys. Discuss., 5, 4429-4475, 2005 b.

Errera, Q. and Fonteyn, D.: Four-dimensional variational chemical assimilation of CRISTA stratospheric measurements, J. Geophys. Res., 106, 12 253-12 265, 2001.

European Space Agency: MIPAS Product Handbook, issue 1.2, available from http://envisat.esa.int/dataproducts, 2004.

Fierli, F., Hauchecorne, A., Bekki, S., Theodore, B., and Fanton D'Andon, O.: Data assimilation of stratospheric ozone using a high-resolution transport model, Geophys. Res. Lett., 29, doi:10.1029/2001GL014272, 2002.

Fischer, H. and Oelhaf, H.: Remote sensing of vertical profiles of atmospheric trace constituents with MIPAS limb-emission spectrometers, Appl. Opt., 35, 2787-2796, 1996.

Fischer, H. and Oelhaf, H.: Summary of the MIPAS validation results, Proceedings of the Second Workshop on the Atmospheric Chemistry Validation of Envisat (ACVE-2), 3-7 May 2004, ESA-ESRIN, Frascati, Italy, ESA SP-562, http://envisat. esa.int/workshops/acve2/contents.html, 2004.

Fisher, M.: Background error covariance modelling, Proceedings of the ECMWF Seminar on recent developments in data assimilation from atmosphere and ocean, 8-12 September 2003, ECMWF, Reading, UK, pp. 45-64, 2003.

Fisher, M. and Andersson, E.: Developments in 4D-Var and Kalman Filtering, ECMWF Technical Memoranda, 347, 2001.

Fisher, M. and Lary, D. J.: Lagrangian 4-dimensional variational data assimilation of chemical-species, Q. J. R. Meteorol. Soc., 121, 1681-1704, 1995.

Fortuin, J. P. F. and Kelder, H.: An ozone climatology based on ozonesonde and satellite measurements, J. Geophys. Res., 103, 31 709-31 734, 1998.

Fortuin, J. P. F. and Langematz, U.: An update on the global ozone climatology and on concurrent ozone and temperature trends, SPIE Proceedings Series, Atmos. Sens. Modeling, Vol. 2311, pp. 207-216, 1995.

Gates, W. L.: AMIP: The Atmospheric Model Intercomparison Project, Bull. Am. Met. Soc., 73, 1962-1970, 1992.

Gauthier, P., Chouinard, C., and Brasnett, B.: Quality control: Methodology and applications, Data Assimilation for the Earth System, edited by: Swinbank, R., Shutyaev, V., and Lahoz, W. A.: Kluwer Academic Publications, Dordrecht, The Netherlands, pp. 177-187, 2003.

Geer, A. J., Lahoz, W. A., Jackson, D. R., Cariolle, D., and McCormack, J. P.: Evaluation of linear ozone photochemistry parametrizations in a stratosphere-troposphere data assimilation system, Atmos. Chem. Phys. Discuss., 6, 7427-7469, 2006 a.

Geer, A. J., Peubey, C., Bannister, R. N., Brugge, R., Jackson, D. R., Lahoz, W. A., Migliorini, S., O’Neill, A., and Swinbank, R.: Assimilation of stratospheric ozone from MIPAS into a global general circulation model: the September 2002 vortex split, Q. J. R. Meteorol. Soc., 132, 231-257, 2006b.

Hervig, M. and McHugh, M.: Cirrus detection using HALOE mea- 
surements, Geophys. Res. Lett., 26, 719-722, 1999.

Hudson, R. D., Frolov, A. D., Andrade, M. F., and Follette, M. B.: The total ozone field separated into meteorological regimes. Part I: defining the regimes, J. Atmos. Sci., 60, 1669-1677, 2003.

Jackson, D. R.: Improvements in data assimilation at the Met Office, Met Office Forecasting Research Technical Report, 454, 2004.

Jackson, D. R. and Saunders, R.: Ozone Data Assimilation: Preliminary System, Met Office Forecasting Research Technical Report, 394, 2002.

Josse, B., Simon, P., and Peuch V.-H.: Radon global simulations with the multiscale chemistry and transport model MOCAGE, Tellus, 56B, 339-356, 2004.

Juckes, M. N.: Evaluation of MIPAS ozone fields assimilated using a new algorithm constrained by isentropic tracer advection, Atmos. Chem. Phys., 6, 1549-1565, 2006a.

Juckes, M. N.: An annual cycle of long lived stratospheric gases from MIPAS, Atmos. Chem. Phys. Discuss., 6, 9389-9429, 2006b.

Kalnay, E.: Atmospheric modeling, data assimilation and predictability, Cambridge University Press, UK, 2003.

Khattatov, B. V., Lamarque, J. F., Lyjak, L. V., Ménard, R., Levelt, P., Tie, X. X., Brasseur, G. P., and Gille, J. C.:, Assimilation of satellite observations of long-lived chemical species in global chemistry transport models, J. Geophys. Res., 105, 29 135-29 144, 2000.

Komhyr, W. D., Barnes, R. A., Brothers, G. B., Lathrop, J. A., and Opperman, D. P.: Electrochemical Concentration Cell Ozonesonde Performance Evaluation During STOIC 1989, J. Geophys. Res., 100, 9231-9244, 1995.

Lagarde, T., Piacentini, A., and Thual, O.: A New Representation of Data Assimilation Methods: the PALM Flow Charting Approach, Q. J. R. Meteorol. Soc., 127, 189-207, 2001.

Lahoz, W. A., Geer, A. J., and O'Neill, A.: Dynamical evolution of the 2003 southern hemisphere stratospheric winter using Envisat trace-gas observations, Q. J. R. Meteorol. Soc., 132, 1985-2008, 2006.

Larsen, N.: Polar Stratospheric Clouds. Microphysical and optical models, Scientific report 00-06, Danish Meteorological Institute, available from http://www.dmi.dk/, 2000.

Lefèvre, F., Brasseur, G. P., Folkins, I., Smith, A. K., and Simon, P.: Chemistry of the 1991-1992 stratospheric winter: threedimensional model simulations, J. Geophys. Res., 99(D4), 81838195, 1994.

Lefèvre, F., Figarol, F., Carslaw, K. S., and Peter, T.: The 1997 Arctic ozone depletion quantified from three-dimensional model simulations, Geophys. Res. Lett., 25, 2425-2428, 1998.

Li, D. and Shine K. P.: A 4-dimensional ozone climatology for UGAMP models, UGAMP Int. Rep., 35, April 1995.

Logan, J. A.: An analysis of ozonesonde data for the troposphere: Recommendations for testing 3-D models and development of a gridded climatology for tropospheric ozone, J. Geophys. Res., 104, 16 115-16 149, 1999.

Lorenc, A. C., Ballard, S. P., Bell, R. S., Ingleby, N. B., Andrews, P. L. F., Barker, D. M., Bray, J. R., Clayton, A. M., Dalby, T. D., Li, D., Payne, T. J., and Saunders, F. W.: The Met. Office global three-dimensional variational data assimilation scheme, Q. J. R. Meteorol. Soc., 126, 2991-3012, 2000.

McCormack, J. P., Eckermann, S. D., Coy, L., Allen, D. R., Kim, Y.-
J., Hogan, T., Lawrence, B., Stephens, A., Browell, E. V., Burris, J., McGee, T., and Trepte, C. R.: NOGAPS-ALPHA model simulations of stratospheric ozone during the SOLVE2 campaign, Atmos. Chem. Phys., 4, 2401-2423, 2004,

http://www.atmos-chem-phys.net/4/2401/2004/.

McLinden, C. A., Olsen, S. C., Hannegan, B., Wild, O., Prather, M. J., and Sundet, J.: Stratospheric ozone in 3-D models: A simple chemistry and the cross-tropopause flux, J. Geophys. Res., 105, 14 653-14 665, 2000.

McPeters, R. D., Bhartia, P. K., Krueger, A. J., Herman, J. R., Wellemeyer, C. G., Seftor, C. J., Jaross, G., Torres, O., Moy, L., Labow, G., Byerly, W., Taylor, S. L., Swissler, T., and Cebula, R. P.: Earth Probe Total Ozone Mapping Spectrometer (TOMS) Data Products User's Guide, NASA Technical Publication 1998206895, NASA Goddard Space Flight Center, Greenbelt, Maryland 20771, 1998.

Massart, S., Cariolle, D., and Peuch, V.-H.: Towards an improvement of the atmospheric ozone distribution and variability by assimilation of satellite data, C. R. Geosciences, 15, 1305-1310, 2005.

Migliorini, S., Piccolo, C., and Rodgers, C. D.: Intercomparison of direct and indirect measurements: Michelson Interferometer for Passive Atmospheric Sounding (MIPAS) versus sonde ozone profiles, J. Geophys. Res., 109, D19316, doi:10.1029/2004JD004988, 2004.

Morcrette, J. J.: Ozone-radiation interactions in the ECMWF forecast system, ECMWF Technical Memoranda, 375, 2003.

Pawson, S., Kodera, K., Hamilton, K., Shepherd, T. G., Beagley, S. R., Boville, B. A., Farrara, J. D., Fairlie, T. D. A., Kitoh, A. Lahoz, W. A., Langematz, U., Manzini, E., Rind, D. H., Scaife, A. A., Shibata, K., Simon, P., Swinbank, R., Takacs, L., Wilson, R. J., Al-Saadi, J. A., Amodei, M., Chiba, M., Coy, L., de Grandpré, J., Eckman, R. S., Fiorino, M., Grose, W. L., Koide, H., Koshyk, J. N., Li, D., Lerner, J., Mahlman, J. D., McFarlane, N. A., Mechoso, C. R., Molod, A., O’Neill, A., Pierce, R. B., Randel, W. J., Rood, R. B., and Wu, F.: The GCM-Reality Intercomparison Project for SPARC (GRIPS): Scientific Issues and Initial Results, Bull. Am. Met. Soc., 81, 781-796, 2000.

Peuch, A., Thépaut, J.-N., and Pailleux, J.: Dynamical impact of total-ozone observations in a four-dimensional variational assimilation, Q. J. R. Meteorol. Soc., 126, 1641-1659, 2000.

Plumb, R. A.: Stratospheric transport, J. Meteorol. Soc. Jpn., 80, 793-809, 2002.

Rabier, F., Jarvinen, H., Klinker, E., Mahfouf, J. F., and Simmons, A.: The ECMWF operational implementation of fourdimensional variational assimilation. I: Experimental results with simplified physics, Q. J. R. Meteorol. Soc., 126, 1148-1170, 2000.

Randel, W., Udelhofen, P., Fleming, E., Geller, M., Gelman, M., Hamilton, K., Karoly, D., Ortland, D., Pawson, S., Swinbank, R., Wu, F., Baldwin, M., Chanin, M. L., Keckhut, P., Labitzke, K., Remsberg, E., Simmons, A., and Wu, D.: The SPARC intercomparison of middle-atmosphere climatologies, J. Climate, 17, 986-1003, 2004.

Raspollini P., Belotti C., Burgess A., Carli B., Carlotti M., Ceccherini S., Dinelli B. M., Dudhia A., Flaud J.-M., Funke B., Höpfner M., Lopez-Puertas M., Payne V., Piccolo C., Remedios J. J., Ridolfi M., and Spang R.: MIPAS level 2 operational analysis, Atmos. Chem. Phys. Discuss., 6, 6525-6585, 2006, 
http://www.atmos-chem-phys-discuss.net/6/6525/2006/.

Riishøjgaard, L. P.: On four-dimensional variational assimilation of ozone data in weather-prediction models, Q. J. R. Meteorol. Soc., 122, 1545-1571, 1996.

Rodgers, C. D.: Inverse Methods for Atmospheric Sounding: Theory and Practice, World Scientific Publishing, Singapore, 2000.

Roelofs, G. J., Kentarchos, A. S., Trickl, T., Stohl, A., Collins, W. J., Crowther, R. A., Hauglustaine, D., Klonecki, A., Law, K. S., Lawrence, M. G., von Kuhlmann, R., and van Weele, M.: Intercomparison of tropospheric ozone models: Ozone transport in a complex tropopause folding event, J. Geophys. Res., 108, 8529, doi:10.1029/2003JD003462, 2003.

Russell, J. M., Gordley, L. L., Park, J. H., Drayson, S. R., Hesketh, W. D., Cicerone, R. J., Tuck, A. F., Frederick, J. E., Harries, J. E., and Crutzen, P. J.: The Halogen Occultation Experiment, J. Geophys. Res., 98, 10777-10 797, 1993.

Sassi, F., Boville, B. A., Kinnison, D., and Garcia, R. R.: The effects of interactive ozone chemistry on simulations of the middle atmosphere, Geophys. Res. Lett., 32, L07811, doi:10.1029/2004GL022131, 2005.

Scheele, M. P., Siegmund, P. C., and van Velthoven, P. F. J.: Stratospheric age of air computed with trajectories based on various 3D-Var and 4-D-Var data sets, Atmos. Chem. Phys., 5, 1-7, 2005, http://www.atmos-chem-phys.net/5/1/2005/.

Schoeberl, M. R., Douglass, A. R., Zhu, Z. X., and Pawson, S.: A comparison of the lower stratospheric age spectra derived from a general circulation model and two data assimilation systems, J. Geophys. Res., 108, 4113, doi:10.1029/2002JD002652, 2003.

Segers, A. J., Eskes, H. J., Van Der A, R. J., Van Oss, R. F., and Van Velthoven, P. F. J.: Assimilation of GOME ozone profiles and a global chemistry transport model using a Kalman filter with anisotropic covariance, Q. J. R. Meteorol. Soc., 131, 477-502, 2005a.

Segers, A. J., Von Savigny, C., Brinksma, E. J., and Piters, A. J. M.: Validation of IFE-1.6 SCIAMACHY limb ozone profiles, Atmos. Chem. Phys., 5, 3045-3052, 2005b.

Spiegel, M. R. and Stephens, L. J.: Schaum's Outline of Theory and Problems of Statistics, 3rd Ed., McGraw-Hill, New York, 538pp., 1999.

Stajner, I., Riishøjgaard, L. P., and Rood, R. B.: The GEOS ozone data assimilation system: Specification of error statistics, Q. J. R. Meteorol. Soc., 127, 1069-1094, 2001.

S̆tajner, I., Winslow, N., Rood, R. B., and Pawson, S.: Monitoring of observation errors in the assimilation of satellite ozone data, J. Geophys. Res., 109, D06309, doi:10.1029/2003JD004118, 2004.

Stohl, A., Cooper, O. R., and James, P.: A cautionary note on the use of meteorological analysis fields for quantifying atmospheric mixing, J. Atmos. Sci., 61, 1446-1453, 2004.

Struthers, H., Brugge, R., Lahoz, W. A., O’Neill, A., and Swinbank, R.: Assimilation of ozone profiles and total column measurements into a global general circulation model, J. Geophys. Res., 107, 4438, doi:10.1029/2001JD000957, 2002.
Talagrand, O.: A posteriori validation of assimilation algorithms, Data Assimilation for the Earth System, edited by: Swinbank, R., Shutyaev, V., and Lahoz, W. A., Kluwer Academic Publications, Dordrecht, The Netherlands, 85-95, 2003.

Tan, W. W., Geller, M. A., Pawson, S., and da Silva, A.: A case study of excessive subtropical transport in the stratosphere of a data assimilation system, J. Geophys. Res., 109, D11102, doi:10.1029/2003JD004057, 2004.

Thompson, A. M., Witte, J. C., McPeters, R. D., Oltmans, S. J., Schmidlin, F. J., Logan, J. A., Fujiwara, M., Kirchhoff, V. W. J. H., Posny, F., Coetzee, G. J. R., Hoegger, B., Kawakami, S., Ogawa, T., Johnson, B. J., Vomel, H., and Labow, G.: Southern Hemisphere Additional Ozonesondes (SHADOZ) 1998-2000 tropical ozone climatology - 1. Comparison with Total Ozone Mapping Spectrometer (TOMS) and ground-based measurements, J. Geophys. Res., 108, 8238, doi:10.1029/2001JD000967, 2003a.

Thompson, A. M., Witte, J. C., Oltmans, S. J., Schmidlin, F. J., Logan, J. A., Fujiwara, M., Kirchhoff, V. W. J. H., Posny, F., Coetzee, G. J. R., Hoegger, B., Kawakami, S. J., Ogawa, T., Fortuin, J. P. F., and Kelder, H. M.: Southern Hemisphere Additional Ozonesondes (SHADOZ) 1998-2000 tropical ozone climatology -2 . Tropospheric variability and the zonal wave-one, J. Geophys. Res., 108, 8241, doi:10.1029/2002JD002241, 2003b.

Uppala, S. M., Kållberg, P. W., Simmons, A. J., Andrae, U., da Costa Bechtold, V., Fiorino, M., Gibson, J. K., Haseler, J., Hernandez, A., Kelly, G. A., Li, X., Onogi, K., Saarinen, S., Sokka, N., Allan, R. P., Andersson, E., Arpe, K., Balmaseda, M. A., Beljaars A. C. M., Van De Berg, L., Bidlot, J., Bormann, N., Caires, S., Chevallier, F., Dethof, A., Dragosavac, M., Fisher, M., Fuentes, M., Hagemann, S., Hólm, E., Hoskins, B. J., Isaksen, L., Janssen, P. A. E. M., Jenne, R., McNally, A. P., Mahfouf, J-F., Morcrette, J-J., Rayner, N. A., Saunders, R. W., Simon, P., Sterl, A., Trenberth, K. E., Untch, A., Vasiljevic, D., Viterbo, P., and Woollen, J.: The ERA-40 re-analysis, Q. J. R. Meteorol. Soc., 131, 2961-3012, 2005.

Wargan, K., Stajner, I., Pawson, S., and Rood, R. B.: Monitoring and Assimilation of Ozone Data from the Michelson Interferometer for Passive Atmospheric Sounding, Q. J. R. Meteorol. Soc., 131, 2713-2734, 2005.

Weaver, A. and Courtier, P.: Correlation modelling on the sphere using a generalized diffusion equation, Q. J. R. Meteorol. Soc., 127, 1815-1846, 2001.

World Meteorological Organisation: Scientific assessment of ozone depletion: 2002, Global Ozone Research and Monitoring Project-Report No. 47, 498 pp., Geneva, 2003.

Z̆agar, N.: Assimilation of equatorial waves by line-of-sight wind observations, J. Atmos. Sci., 61, 1877-1893, 2004. 